\title{
Satellite-derived volume loss rates and glacier speeds for the Cordillera Darwin Icefield, Chile
}

\author{
A. K. Melkonian ${ }^{1}$, M. J. Willis ${ }^{1}$, M. E. Pritchard ${ }^{1}$, A. Rivera ${ }^{2,3}$, F. Bown ${ }^{2}$, and S. A. Bernstein ${ }^{4}$ \\ ${ }^{1}$ Department of Earth and Atmospheric Sciences, Cornell University, Ithaca, New York, USA \\ ${ }^{2}$ Centro de Estudios Científicos (CECs), Valdivia, Chile \\ ${ }^{3}$ Departamento de Geografía, Universidad de Chile, Santiago, Chile \\ ${ }^{4}$ St. Timothy's School, 8400 Greenspring Ave, Stevenson, MD 21153, USA
}

Correspondence to: A. K. Melkonian (akm26@ cornell.edu)

Received: 12 July 2012 - Published in The Cryosphere Discuss.: 31 August 2012

Revised: 30 March 2013 - Accepted: 17 April 2013 - Published: 14 May 2013

Abstract. We produce the first icefield-wide volume change rate and glacier velocity estimates for the Cordillera Darwin Icefield (CDI), a $2605 \mathrm{~km}^{2}$ temperate icefield in southern Chile $\left(69.6^{\circ} \mathrm{W}, 54.6^{\circ} \mathrm{S}\right)$. Velocities are measured from optical and radar imagery between 2001-2011. Thirty-six digital elevation models (DEMs) from ASTER and the SRTM DEM are stacked and a weighted linear regression is applied to elevations on a pixel-by-pixel basis to estimate volume change rates.

The CDI lost mass at an average rate of $-3.9 \pm 1.5 \mathrm{Gt} \mathrm{yr}^{-1}$ between 2000 and 2011, equivalent to a sea level rise (SLR) of $0.01 \pm 0.004 \mathrm{~mm} \mathrm{yr}^{-1}$ and an area-averaged thinning rate of $-1.5 \pm 0.6 \mathrm{~m}$ w.e. (water equivalent) $\mathrm{yr}^{-1}$.

Thinning is widespread, with concentrations near the front of two northern glaciers (Marinelli, Darwin) and one western (CDI-08) glacier. Thickening is apparent in the south, most notably over the advancing Garibaldi Glacier. The northeastern part of the CDI has an average thinning rate of $-1.9 \pm 0.7 \mathrm{~m}$ w.e. $\mathrm{yr}^{-1}$, while the southwestern part has an average thinning rate of $-1.0 \pm 0.4 \mathrm{~m}$ w.e. $\mathrm{yr}^{-1}$.

Velocities are obtained over many of the CDI glaciers for the first time. We provide a repeat speed time series at the Marinelli Glacier. There we measure maximum front speeds of $7.5 \pm 0.2 \mathrm{mday}^{-1}$ in $2001,9.5 \pm 0.6 \mathrm{mday}^{-1}$ in 2003 and $10 \pm 0.3 \mathrm{~m} \mathrm{day}^{-1}$ in 2011 . The maintenance of high front speeds from 2001 to 2011 supports the hypothesis that Marinelli is in the retreat phase of the tidewater cycle, with dynamic thinning governed by the fjord bathymetry.

\section{Introduction}

We focus on the Cordillera Darwin Icefield (CDI), the third largest temperate icefield in the Southern Hemisphere (Bown et al., 2013), which along with the Northern Patagonian Icefield (NPI) and Southern Patagonian Icefield (SPI), has experienced a rapid reduction in ice-covered area (Rivera et al., 2007; Masiokas et al., 2009; Lopez et al., 2010; Davies and Glasser, 2012; Willis et al., 2012b). The CDI is located in the southernmost Andes (Fig. 1) in Tierra del Fuego. It is coalesced around two main mountain peaks, Mount Darwin (2469 m a.s.l., Koppes et al., 2009) and the nearby Mount Sarmiento (2300 m a.s.1., Strelin et al., 2008). The icefield covers $2605 \mathrm{~km}^{2}$, measured from ice outlines derived from satellite imagery acquired from 2001 to 2004. It extends roughly $200 \mathrm{~km}$ west-east from $71.8^{\circ} \mathrm{W}$ to $68.5^{\circ} \mathrm{W}$ and roughly $50 \mathrm{~km}$ south-north from $54.9^{\circ} \mathrm{S}$ to $54.2^{\circ} \mathrm{S}$, boardered to the north by the Almirantazgo Fjord and the Beagle Channel in the south. Precipitation during the winter comes predominantly from the south/southwest (Holmlund and Fuenzalida, 1995), and the E-W orientation of the CDI leads to an orographic effect with greater snowfall on southern and western glaciers and drier, warmer conditions on northern and eastern glaciers (Holmlund and Fuenzalida, 1995; Strelin and Iturraspe, 2007; Koppes et al., 2009; Lopez et al., 2010). Previous length-change measurements of CDI glaciers show retreat at northern and eastern glaciers and stable/advancing fronts at southern and western glaciers (Holmlund and Fuenzalida, 1995). The "southern" part or side of the CDI refers to southern and western glaciers, and the 


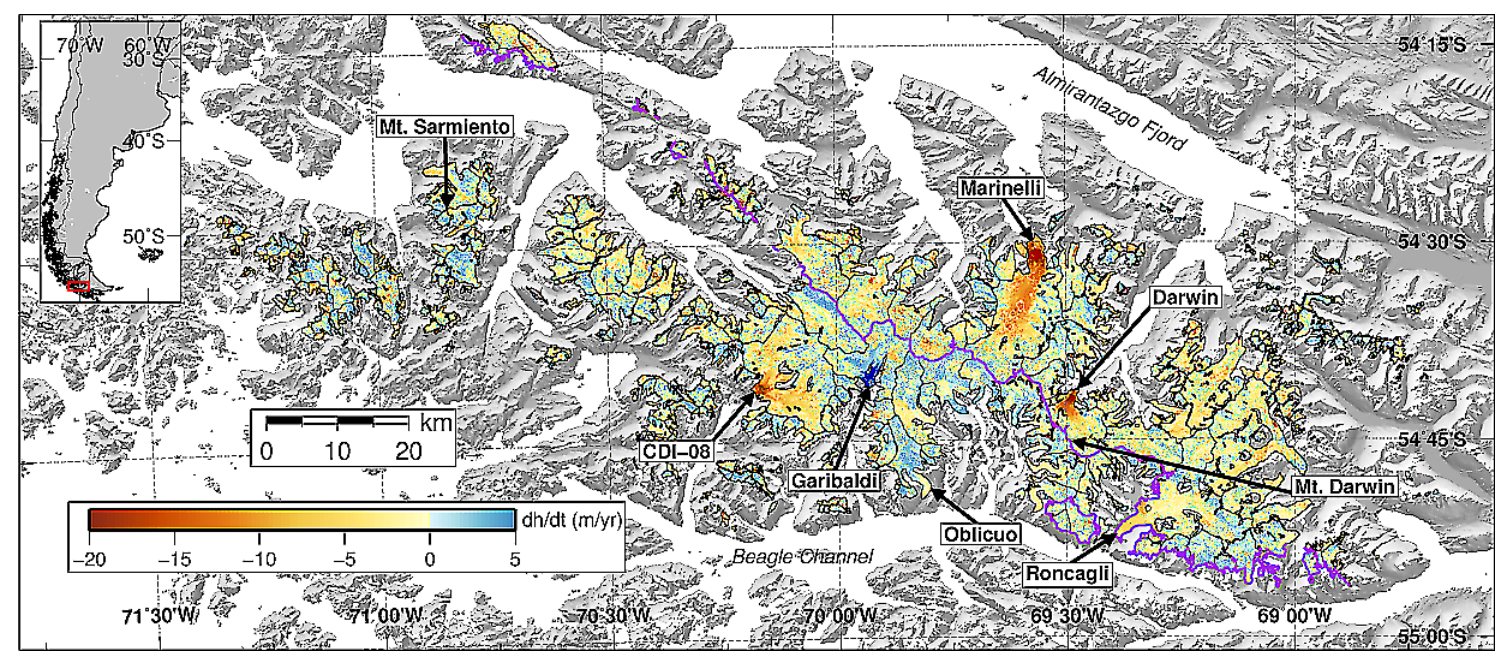

Fig. 1. Map of $\frac{\mathrm{d} h}{\mathrm{~d} t}$ for the CDI (area indicated by red box in inset). Three glaciers, Marinelli, Darwin, and CDI-08, stand out with extensive thinning towards their fronts. The purple line indicates the divide between the "northern" and "southern" regions of the CDI.

"northern" part or side of the CDI refers to northern and eastern glaciers. The purple line in Fig. 1 shows the divide between the northern $\left(1322 \mathrm{~km}^{2}\right)$ and southern $\left(1283 \mathrm{~km}^{2}\right)$ sides.

There are few studies on the CDI compared to other temperate ice fields (Masiokas et al., 2009; Lopez et al., 2010), such as the Alaskan ice fields, the NPI and the SPI (e.g., Arendt et al., 2002; Rignot et al., 2003; Berthier et al., 2010; Glasser et al., 2011; Ivins et al., 2011; Willis et al., 2012a). Climate and mass balance studies are scarce for southern hemispheric ice bodies outside of Antarctica (Holmlund and Fuenzalida, 1995; Lopez et al., 2010), due to the difficult access and weather.

Studies of observational and reanalysis data indicate the loss of ice at the CDI can be attributed to climatic changes that include 20th century regional decreases in precipitation (Quintana, 2004) coupled with atmospheric warming (Holmlund and Fuenzalida, 1995; Lopez et al., 2010) and dynamic instability at the largest glacier on the icefield, Marinelli (e.g., Holmlund and Fuenzalida, 1995). On a local scale, changes in wind patterns have increased precipitation on the southern side of the CDI (Holmlund and Fuenzalida, 1995; Strelin and Iturraspe, 2007), while decreasing precipitation on the northern side (Holmlund and Fuenzalida, 1995; Koppes et al., 2009).

Temperate ice fields are disproportionately large contributors to SLR (e.g., Arendt et al., 2002; Rignot et al., 2003); Rignot et al. (2003) claim this is particularly true of the Patagonian glaciers, which they say account for $9 \%$ of the nonpolar contribution to SLR. The CDI, along with the NPI and SPI, provides an opportunity to examine the response of different glaciers (e.g., calving vs. noncalving) in different climates (maritime on the southern side versus more continental on the northern side) to regional changes in climate
(Holmlund and Fuenzalida, 1995), and unlike the NPI and SPI the contribution of the CDI to SLR has not yet been estimated (Lopez et al., 2010).

The CDI is the closest icefield to the Antarctic Peninsula, a region that has also experienced significant warming. Mass loss at the CDI might be contaminating GRACE measurements of the Antarctic Peninsula, NPI and SPI (Ivins et al., 2011), so our constraints on the mass loss rate occurring at the CDI will help isolate this signal. Thinning and acceleration have been observed on glaciers in the Antarctic Peninsula and the NPI (Pritchard and Vaughan, 2007; Willis et al., 2012a), we assess whether this is the case for any glaciers on the CDI.

In this study we calculate both the elevation change rates $\left(\frac{\mathrm{d} h}{\mathrm{~d} t}\right)$ over the entire CDI and measure glacier velocities using pixel-tracking applied to pairs of optical and radar images. With $\frac{\mathrm{d} h}{\mathrm{~d} t}$ and an assumed density of material lost/gained, we can estimate the mass change rate, allowing us to quantify its SLR contribution and compare it with other ice fields. We also use the surface elevation change rates to identify which glaciers are providing the largest contribution to SLR and should be the focus of further study. Additionally, measuring glacier velocities allows an estimate of mass flux out of the glacier if the thickness is known. Increased speed and mass flux through the front of the glacier can cause "dynamic thinning" if it is not balanced by increased mass input. Our results will provide a baseline measurement over many glaciers and areas of the icefield for which ice velocities have not been measured.

The date format used throughout this paper is DD/MM/YYYY. 


\section{Methods}

\subsection{Data Preparation}

The Advanced Spaceborne Thermal Emission and Reflection Radiometer (ASTER) has a stereo-imaging capability, enabling DEMs to be generated on-demand by NASA's Land Processes Distributed Active Archive Center (LP DAAC) (Fujisada et al., 2005). In this study, ASTER DEMs (product 14) are used to calculate $\frac{\mathrm{d} h}{\mathrm{~d} t}$, while band $3 \mathrm{~N}$ images (product 1B) are used for pixel-tracking. Clouds are not masked during data preparation, rather, they are largely removed by excluding elevations based on deviation from the the SRTM DEM (Sect. 2.2). NASA's Automatic Registration and Orthorectification Package (AROP; Gao et al., 2009) is used to co-register ASTER images and DEMs to a Landsat GLS image (available from the Global Land Cover Facility) and orthorectify the ASTER L1B images using the Shuttle Radar Topography Mission (SRTM) DEM (acquired in 2000). Landsat GLS images are orthorectified to the SRTM DEM (Tucker et al., 2004); therefore, co-registering the ASTER imagery to the Landsat GLS image effectively coregisters them to the SRTM DEM (see Willis et al., 2012a for details). The SRTM DEM is our default DEM for orthorectifying the ASTER imagery; it is not as adversely affected by clouds, snow and other features that cause errors in optically derived (e.g., ASTER) DEMs (Scherler et al., 2008). All ASTER images used for pixel-tracking are orthorectified to the SRTM DEM, except for the $07 / 09 / 2001$ to $25 / 09 / 2001$ and $06 / 09 / 2003$ to $13 / 09 / 2003$ pairs covering the front of Marinelli Glacier, where pronounced thinning necessitates the use of the corresponding ASTER DEMs. These pairs are orthorectified to the $25 / 09 / 2001$ and $13 / 09 / 2003$ ASTER DEMs, respectively.

\subsection{Elevation change rates}

Horizontally co-registered ASTER DEMs are subsequently vertically co-registered and a weighted linear regression is applied to calculate $\frac{\mathrm{d} h}{\mathrm{~d} t}$ for each pixel. In all, 36 ASTER DEMs (derived from imagery acquired from 2001 to 2011) and the SRTM DEM (acquired in February 2000) are processed, with an average of 4-5 elevations per pixel incorporated into the regression (Fig. 2 shows elevations and regression lines for several points on Marinelli Glacier). Each elevation is weighted by the inverse of the standard deviation of the bedrock elevation differences between its ASTER DEM and the SRTM DEM. This is a common measure of the uncertainty associated with ASTER DEM elevations (Fujisada et al., 2005; Howat et al., 2008). Horizontal misalignment will appear as off-ice ("bedrock") elevation differences when comparing ASTER DEMs to the SRTM DEM, and is therefore included in the standard deviation of the bedrock elevation differences (i.e., the greater the misalignment, the greater the standard deviation, which is the measure of un- certainty that we use for each ASTER DEM). We typically find values from $8 \mathrm{~m}$ to $20 \mathrm{~m}$ as our uncertainty for ASTER DEMs, similar to other studies (Kääb, 2002; Fujisada et al., 2005; San and Süzen, 2005; Rivera et al., 2007; Howat et al., 2008; Berthier et al., 2010).

In the ablation zone, we exclude elevations from the regression that deviate more than $+5 /-30 \mathrm{~m} \mathrm{yr}^{-1}$ from the first elevation, in the accumulation zone the cutoff is $+5 /-10 \mathrm{~m} \mathrm{yr}^{-1}$. These cutoffs largely remove the areas of erroneously high elevations due to clouds, as well as outliers caused by shadow, snow and other sources which either obscure the ice or are largely featureless at ASTER resolution. It is important to note that although these cutoffs are based on expected $\frac{\mathrm{d} h}{\mathrm{~d} t}$, they are imposed on each individual map point (see Fig. 2) before applying the weighted linear regression, rather than to already calculated $\frac{\mathrm{d} h}{\mathrm{~d} t}$, which would yield drastically different results. The first elevation in our time series is SRTM for $94 \%$ of the pixels, for the remaining areas we use the first available elevation from ASTER. The average end date is $17 / 05 / 2008$. The high percentage of points with SRTM elevations makes our cutoff strategy feasible. The radar-derived SRTM DEM is not influenced by clouds like ASTER, making SRTM elevations a reliable starting point.

We limit the maximum negative deviation to $-30 \mathrm{~m} \mathrm{yr}^{-1}$ in the ablation zone to just capture the maximum thinning and exclude spurious elevations from the regression calculations. Changing this to $-60 \mathrm{~m} \mathrm{yr}^{-1}$ has no affect on the zones of maximum thinning. Less thinning is expected in the accumulation zone than in the ablation zone; therefore, we allow a maximum negative deviation of only $-10 \mathrm{~m} \mathrm{yr}^{-1}$ above the ELA. Permitting a greater negative deviation in the accumulation zone only results in incoherent areas of extreme and unrealistic thinning.

In order to determine the ELA and distinguish where to impose our different constraints, we examine late season (January and February) ASTER images. We record the altitude of the transition between bare ice and snow and take this as a rough proxy for the ELA (e.g., Bamber and Rivera, 2007). We are able to measure the ELA for 11 larger glaciers, for the rest of the icefield, we assume a regional ELA of $1090 \mathrm{~m}$ (Strelin and Iturraspe, 2007).

The volume change rate at each pixel is the $\frac{\mathrm{d} h}{\mathrm{~d} t}$ for the pixel multiplied by the area of the pixel. Summing together the volume change rate of every pixel yields a volume change rate $\left(\frac{\mathrm{d} V}{\mathrm{~d} t}\right)$ for the entire icefield. $\frac{\mathrm{d} V}{\mathrm{~d} t}$ is multiplied by the density of glacier ice, set to $900 \mathrm{~kg} \mathrm{~m}^{-3}$ (e.g., Cuffey and Paterson, 2010) to produce an estimate of the mass change rate. Future ground-based measurements of densities on the CDI will be needed to find more accurate and precise values.

We have a sufficient number of ASTER DEMs to provide $\frac{\mathrm{d} h}{\mathrm{~d} t}$ rates for $96 \%$ of the total area of the icefield. Each pixel in the remaining small gaps is filled with the median $\frac{\mathrm{d} h}{\mathrm{~d} t}$ value within $1 \mathrm{~km}$. This local method is more accurate than using 

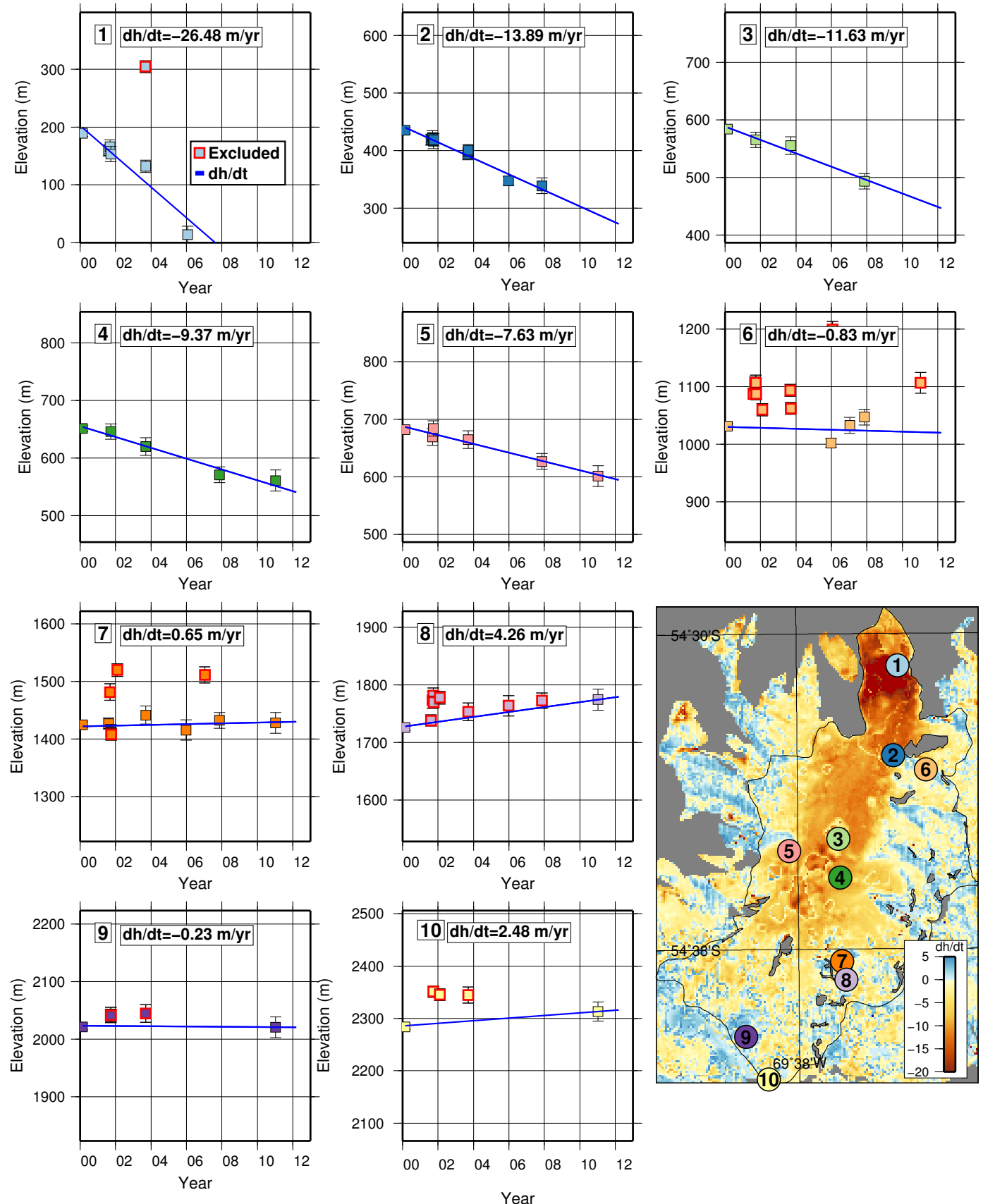

Fig. 2. Elevation values and $\frac{\mathrm{d} h}{\mathrm{~d} t}$ for randomly selected pixels over Marinelli Glacier. The left-most elevation in each graph is the SRTM elevation at that pixel. Blue lines indicate the $\frac{\mathrm{d} h}{\mathrm{~d} t}$ calculated for each pixel, elevation points bolded red are excluded from $\frac{\mathrm{d} h}{\mathrm{~d} t}$ calculation. The bottom right panel shows the $\frac{\mathrm{d} h}{\mathrm{~d} t}$ map, with numbered circles indicating the location corresponding to each graph.

the average $\frac{\mathrm{d} h}{\mathrm{~d} t}$ of an elevation bin to fill gaps within that bin, or filling in gaps with the mean of all $\frac{\mathrm{d} h}{\mathrm{~d} t}$ calculated (e.g., Rignot et al., 2003). For example, the average low-elevation $\frac{\mathrm{d} h}{\mathrm{~d} t}$ and overall average $\frac{\mathrm{d} h}{\mathrm{~d} t}$ are both negative, these rates would not be suitable for filling a gap near the front of Garibaldi Glacier, which is known to be advancing and where we measure positive $\frac{\mathrm{d} h}{\mathrm{~d} t}$ at low elevations.
Penetration of C-band radar into ice and (particularly) snow (e.g., Rignot et al., 2001) is a potential problem when using the SRTM DEM. We use a technique pioneered by Gardelle et al. (2012) and applied by Willis et al. (2012b) to compensate for penetration effects. Willis et al. (2012b) compared X-band SRTM elevations (which have negligible penetration) with C-band SRTM elevations and found 
approximately $2 \mathrm{~m}$ of C-band penetration over the SPI at all elevations. Due to a lack of X-band SRTM coverage over the CDI, we cannot provide a similar analysis here. Instead, we assume the penetration depth is similar to that at SPI and add $2 \mathrm{~m}$ to each SRTM elevation over ice, which increases our mass loss rate by about $13 \%$. We note the CDI is colder than the SPI, which could lead to drier conditions and greater penetration (Rignot et al., 2001), but we do not have adequate $\mathrm{X}$-band data to quantify the difference.

An additional source of mass change that we consider is sub-aqueous mass loss/gain (which does not contribute to sea level rise). We cannot directly measure sub-aqueous ice gains or losses, but make a rough estimate by measuring changes in the areal extent at the front of several glaciers that have undergone relatively large advance or retreat (from image pairs) and multiplying these area changes by the approximate depth below water of the ice. We assume an average depth below water of $150 \mathrm{~m}$ for Marinelli Glacier (see Koppes et al., 2009, Fig. 4a and b) and $60 \mathrm{~m}$ for the other glaciers, with an uncertainty of $\pm 50 \mathrm{~m}$ (the uncertainty on the change in area of each glacier is negligible). Dividing the sub-aqueous volume change by the time interval separating the images used to find area change gives a rate. This calculation shows that subaqueous mass loss, while not well constrained in this study, is an order of magnitude lower than the overall mass change rate calculated from $\frac{\mathrm{d} h}{\mathrm{~d} t}(<5 \%)$.

\subsubsection{Sources of uncertainty}

Below we consider sources of uncertainty on our mass change rate. These include the uncertainty on the elevations incoporated into the regression, uncertainty on the ELA, the effect of varying the maximum deviation allowed from the first elevation, different density scenarios, and uncertainty on the penetration depth of the C-band SRTM DEM.

The uncertainty associated with the $\frac{\mathrm{d} h}{\mathrm{~d} t}$ for each pixel is calculated from the model covariance matrix (e.g., Aster et al., 2005), which accounts for the uncertainties on the elevations incorporated into the regression. The $95 \%$ confidence interval for the volume change rate uncertainty is calculated using the formula: $1.96 \times \frac{U}{\sqrt{N}}$. $U$ is the total "volume" of uncertainty, calculated by taking the uncertainty at each pixel, multiplying it by the area of the pixel (to determine a "volume" of uncertainty for that pixel), and then adding together "volume" of uncertainty for each pixel where a $\frac{\mathrm{d} h}{\mathrm{~d} t}$ is calculated. $N$ is the number of independent pixels (e.g., Howat et al., 2008), which we determine by dividing the total area by the area over which off-ice $\frac{\mathrm{d} h}{\mathrm{~d} t}$ are correlated (e.g., Rolstad et al., 2009). We estimate the scale at which the $\frac{\mathrm{d} h}{\mathrm{~d} t}$ are independent by finding the area at which the variance of the off-ice $\frac{\mathrm{d} h}{\mathrm{~d} t}$ begins to "flatten" (see Rolstad et al., 2009 and Willis et al., 2012a for details on the method), which we estimate to be $1800 \mathrm{~m}$ by $1800 \mathrm{~m}$ (Fig. 4). This is analogous to the "corner" point on an $L$ curve (e.g., Aster et al., 2005, p. 91, Fig. 5.2) and indicates the lengthscale past which the $\frac{\mathrm{d} h}{\mathrm{~d} t}$ are no longer correlated. The total contribution from the uncertainty on individual elevations is $\sim 0.35 \mathrm{Gt} \mathrm{yr}^{-1}$.

The regional ELA is poorly known. In order to investigate the impact of changing the regional ELA on the mass loss rates, we lower our regional ELA from 1090 to $650 \mathrm{~m}$, an ELA that has been found for several glaciers on the southern and western regions of the CDI (Bown et al., 2013). We also assume an uncertainty of $\pm 200 \mathrm{~m}$ on the 11 glaciers where we have estimated the ELA from optical imagery. The difference between the two ELA scenarios is incorporated into our uncertainties $\left(\sim 0.37 \mathrm{Gt} \mathrm{yr}^{-1}\right)$.

The deviation allowed from the first elevation has a large impact on the mass loss rate (e.g., Willis et al., 2012b). The rate produced by allowing $+10 \mathrm{~m} \mathrm{yr}^{-1}$ is contaminated by low clouds but is given as a rough minimum estimate of the mass loss rate. The unsymmetric cutoff $\left(+5 \mathrm{~m} \mathrm{yr}^{-1}\right.$ versus $-10 /-30 \mathrm{~m} \mathrm{yr}^{-1}$ ) may bias our results towards thinning but we argue that an unsymmetric cutoff is more physically justified than a symmetric cutoff. Rapid retreat has been independently observed at Marinelli Glacier (Holmlund and Fuenzalida, 1995; Koppes et al., 2009), from which we know that a large amount of thinning must be occurring. The maximum allowed negative deviation from the first elevation of $-30 \mathrm{~m} \mathrm{yr}^{-1}$ just captures the maximum thinning at Marinelli Glacier (see Fig. 2, point 1).

The cutoff of $+5 \mathrm{~m} \mathrm{yr}^{-1}$ from the first elevation is based on the limited precipitation data available for this region. The upper limit on precipitation in Patagonia is about $10 \mathrm{~m} \mathrm{yr}^{-1}$ (e.g., Holmlund and Fuenzalida, 1995; Rignot et al., 2003; Rasmussen et al., 2007; Koppes et al., 2011), and PRECIS model results show maximum precipitation in the 4000 to $6000 \mathrm{~mm} \mathrm{yr}^{-1}$ range for the CDI (Fernandez et al., 2011). One year of accumulated precipitation undergoes densification into firn and eventually ice and provides much less than $+10 \mathrm{~m} \mathrm{yr}^{-1}$ of elevation change through time, so $+5 \mathrm{~m} \mathrm{yr}^{-1}$ is chosen as a reasonable upper limit on the maximum thickening expected over the large areas covered in this study. We note that a point measurement may yield a $\frac{\mathrm{d} h}{\mathrm{~d} t}$ higher than $+5 \mathrm{~m} \mathrm{yr}^{-1}$ but we would not expect a single point to be representative of sustained thickening rates over square kilometers. Figure 2 highlights the importance of applying this cutoff, cloud-influenced elevations would seriously degrade the quality of our regressions for each pixel. Tests using a higher positive cutoff produced discontinuous and incoherent "splotches" of extreme positive $\frac{\mathrm{d} h}{\mathrm{~d} t}$ that are unrealistic. The only exception is the lower ablation zone of Garibaldi Glacier, where we allow a maximum positive deviation of $+10 \mathrm{~m} \mathrm{yr}^{-1}$ to accommodate the known advance of Garibaldi (Fig. 3).

The sub-panels in Fig. 2 illustrate the problem of using a positive cutoff of $+30 \mathrm{~m} \mathrm{yr}^{-1}$, which would lead to the inclusion of ASTER elevations that are obvious outliers. ASTER elevations in the accumulation zone are generally less reliable due to greater cloud and snow cover (lack of contrast). 


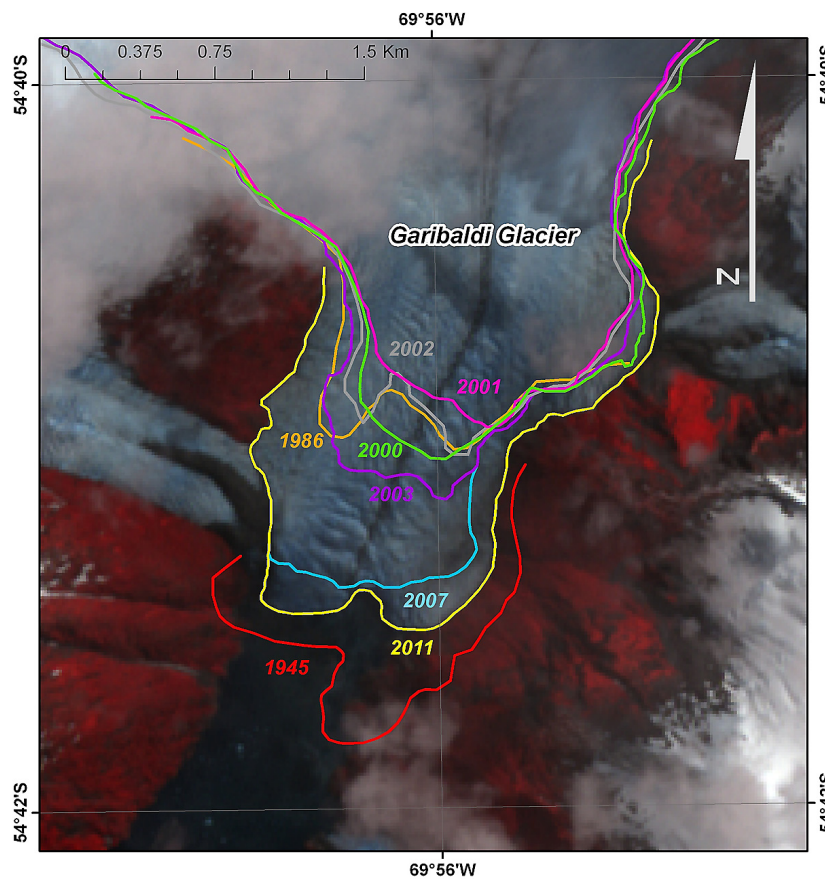

Fig. 3. Frontal variation history of Garibaldi Glacier from Landsat TM, ASTER and aerial photographs. The background is a 15/01/2011 ASTER image.

Errors due to clouds tend to be positive rather than negative; this is confirmed by comparing the average off-ice $\frac{\mathrm{d} h}{\mathrm{~d} t}$ of increasing symmetric maximum allowed deviations. Allowing $\pm 5, \pm 10$ and $\pm 30 \mathrm{~m} \mathrm{yr}^{-1}$ results in average $\frac{\mathrm{d} h}{\mathrm{~d} t}$ of $-0.04 \mathrm{~m} \mathrm{yr}^{-1},+0.10 \mathrm{~m} \mathrm{yr}^{-1}$ and $+0.82 \mathrm{~m} \mathrm{yr}^{-1}$. Allowing a deviation of $-30 \mathrm{~m} \mathrm{yr}^{-1}$ is necessary to capture maximum thinning, but $330 \mathrm{~m}$ of thickening $\left(+30 \mathrm{~m} \mathrm{yr}^{-1}\right.$ from 2000 to 2011 ) is unreasonable in both the ablation and accumulation zone for this region (Koppes et al., 2009; Lopez et al., 2010).

In situ measurements of accumulation rate on the CDI are required to refine our estimates further; the cutoffs we use are the best available based on the literature (e.g., Fernandez et al., 2011). To assess the uncertainty due to the choice of maximum deviation allowed, we find the mode (most frequent occurrence, i.e., peak) of the distribution of elevation differences between all ASTER DEMs and the SRTM DEM (normalized by dividing by the time interval between each ASTER DEM and the SRTM DEM). The mode is not affected by the choice of allowed deviation, and so is an independent measure that we can compare our regression-derived rates to.

We do not present the "mode rate" as representing the best estimate of the average $\frac{\mathrm{d} h}{\mathrm{~d} t}$. It is approximately what the rate would be if the distribution were Gaussian around the peak $\frac{\mathrm{d} h}{\mathrm{~d} t}$. This implicitly assumes that rates that are equidistant from the mode rate are equally likely (e.g., if the mode rate is $-1.5 \mathrm{~m} \mathrm{yr}^{-1}$ ) then rates of $+18.5 \mathrm{~m} \mathrm{yr}^{-1}$ are approximately as common as rates of $-20.5 \mathrm{~m} \mathrm{yr}^{-1}$. We consider

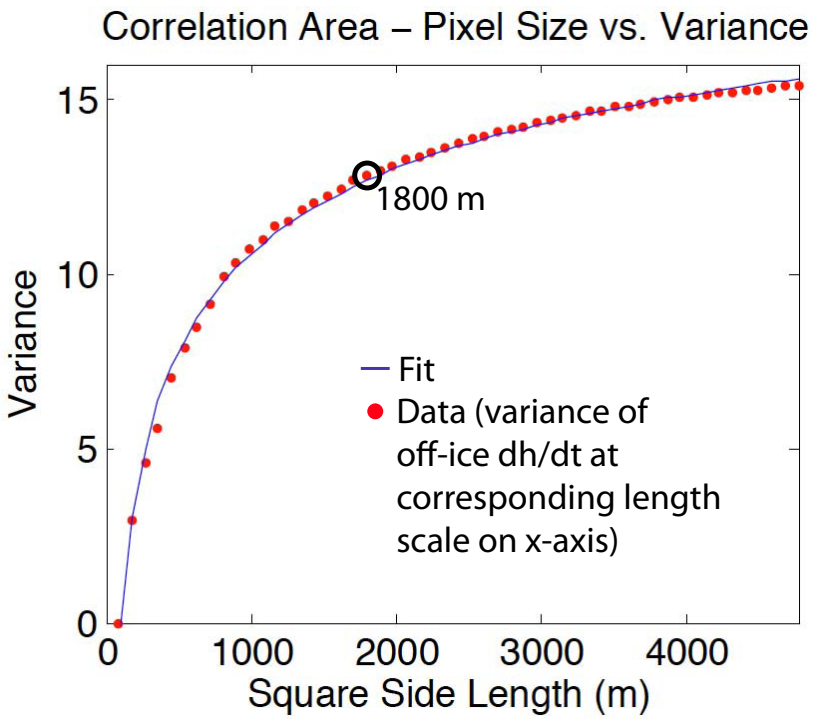

Fig. 4. A plot of pixel size (listed as side length of square pixel) vs. variance of bedrock $\frac{\mathrm{d} h}{\mathrm{~d} t}$ (calculated using a $-10 /+10 \mathrm{~m} \mathrm{yr}^{-1}$ cutoff), plotted as red dots. A linear fit to $\log (x) / y$ shows the trend of the data (blue line). The black circle indicates the point at which the curve is "flattening", i.e., the lengthscale past which the variance no longer changes significantly, indicating that the $\frac{\mathrm{d} h}{\mathrm{~d} t}$ are no longer correlated. $1800 \mathrm{~m}$ is selected as a conservative estimate of the decorrelation length for the $\frac{\mathrm{d} h}{\mathrm{~d} t}$.

this unlikely given the coherent thinning of approximately $-25 \mathrm{~m} \mathrm{yr}^{-1}$ estimated at the front of several glaciers, and the lack of evidence for a similar degree of coherent thickening anywhere on the icefield. Therefore, the mode rate is probably lower than the the actual thinning rate, and the difference between the mode rate and our regression-derived $\frac{\mathrm{d} h}{\mathrm{~d} t}$ is an overestimate of the maximum "bias" due to our choice of $\frac{\mathrm{d} h}{\mathrm{~d} t}$.

We add the difference $\left( \pm 1.22 \mathrm{Gt} \mathrm{yr}^{-1}\right)$ that results from using the same density and penetration assumptions as our regression rate to our uncertainties to fully account for any possible bias.

We assume all volume change is at a density of $900 \mathrm{~kg} \mathrm{~m}^{-3}$, consistent with previous studies (e.g., Rignot et al., 2003; Berthier et al., 2004, 2010). However, the density of the lost material is likely variable. We consider two different density scenarios. Assuming that firn $\left(600 \mathrm{~kg} \mathrm{~m}^{-3}\right)$ is lost in the accumulation zone and ice $\left(900 \mathrm{~kg} \mathrm{~m}^{-3}\right)$ is lost in the ablation zone (considered as a possible scenario by Kääb et al., 2012) reduces the mass change rate by $0.3 \mathrm{Gt} \mathrm{yr}^{-1}$. Assuming an ice density of $900 \pm 25 \mathrm{~kg} \mathrm{~m}^{-3}$ (e.g., Gardner et al., 2012) adds $\pm 0.1 \mathrm{Gt} \mathrm{yr}^{-1}$ to our uncertainty. The effect of density changes are small $(\sim 10 \%)$ as most of the mass loss occurs from ice in the ablation zone. We incorporate the $600 / 900 \mathrm{~kg} \mathrm{~m}^{3}$ scenario into our uncertainties, as it adds a further $\pm 0.3 \mathrm{Gt} \mathrm{yr}^{-1}$ and is thus a more conservative estimate of uncertainty. 
The penetration depth of the C-band SRTM into snow and ice is an additional source of uncertainty. Assuming a range of \pm 2 for the penetration depth yields a variation of $+0.47 \mathrm{Gt} \mathrm{yr}^{-1}$ for $0 \mathrm{~m}$ of penetration and $-0.48 \mathrm{Gt} \mathrm{yr}^{-1}$ for $4 \mathrm{~m}$. We add $\pm 0.48 \mathrm{Gt} \mathrm{yr}^{-1}$ to our uncertainties to account for penetration depth uncertainty.

Taking the square root of the sum of the squared uncertainties gives us an overall uncertainty of $\pm 1.5 \mathrm{Gt} \mathrm{yr}^{-1}$. Uncertainties beyond the statistical uncertainty from the regression are added as an average rate to the uncertainties for individual glacier basins in Table 1 .

\subsection{Velocities}

In this section we describe how we use data from three different satellites with different resolutions to measure sub-pixel offsets and convert them to glacier velocities.

\subsubsection{ASTER}

Sub-pixel offsets between ASTER image pairs (pixel resolution of $15 \mathrm{~m} /$ pixel) are measured via normalized amplitude cross correlation, with a spatial resolution of $120 \mathrm{~m}$ (i.e., a step size between cross correlations of 8 pixels, see Willis et al., 2012a for details). This technique, known as "pixeltracking", has been used to track velocities on many glaciers (e.g., Scambos et al., 1992).

AROP is used to co-register the more recent scene in a pair of orthorectified ASTER images to the earlier scene to minimize misfits. The open source ROI_PAC's "ampcor" routine (Rosen et al., 2004) is used to calculate E$\mathrm{W}$ and $\mathrm{N}-\mathrm{S}$ offsets. The results are post-filtered by excluding offsets with a signal-to-noise ratio (SNR, which is the peak cross correlation value divided by the average) below a manually selected threshold (Willis et al., 2012a). A linear elevation-dependent correction (determined from apparent "bedrock" velocities) is applied to the velocities to correct for the elevation-dependent bias due to imprecise coregistration/orthorectification (Nuth and Kääb, 2011). Figure 5 shows a typical trend for an ASTER pair. We do not know the physical origin of the bias, Ahn and Howat (2011) attribute the systematic elevation-dependent displacement errors over the ice surface to co-registration errors. Applying an elevation-dependent correction based on the displacement of off-ice areas largely removes this (Fig. 6).

Uncertainty for each pair is estimated from motion on ice-adjacent "bedrock" (see Willis et al., 2012a for details), which should be zero. Horizontal misalignment leads to office motions when calculating offsets, so error due to misalignment is included in the uncertainty estimate.

\subsubsection{QuickBird 2}

A high-resolution (1 m/pixel) QB02 image pair from 2011 (30/07/2011-16/08/2011) is run through largely the same processing applied to ASTER image pairs to generate off-
Table 1. Volume change rates and average $\frac{\mathrm{d} h}{\mathrm{~d} t}$ for the 16 largest outlet glaciers on the CDI, with "northern", "southern" and whole icefield totals in the last three rows. Includes estimates of sub-aqueous volume change for Marinelli, CDI-08, Garibaldi and Darwin.

\begin{tabular}{lrcc}
\hline Glacier & $\begin{array}{r}\text { Area } \\
\left(\mathrm{km}^{2}\right)\end{array}$ & $\begin{array}{l}\mathrm{d} V \\
\mathrm{~d} t \\
\left(\mathrm{~km}^{3} \mathrm{yr}^{-1}\right)\end{array}$ & $\begin{array}{l}\text { Average } \frac{\mathrm{d} h}{\mathrm{~d} t} \\
\left(\mathrm{~m} \text { w.e. } \mathrm{yr}^{-1}\right)\end{array}$ \\
\hline Marinelli Glacier & 132.93 & $-0.74 \pm 0.16$ & $5.0 \pm 1.1$ \\
CDI-08 Glacier & 127.42 & $-0.43 \pm 0.13$ & $-3.0 \pm 0.9$ \\
Roncagli Glacier & 116.06 & $-0.18 \pm 0.15$ & $-1.4 \pm 1.2$ \\
Stoppani Glacier & 102.04 & $-0.2 \pm 0.12$ & $-1.8 \pm 1.1$ \\
Garibaldi Glacier & 63.86 & $0.02 \pm 0.13$ & $0.2 \pm 1.8$ \\
CDI_157 Glacier & 57.42 & $-0.11 \pm 0.08$ & $-1.7 \pm 1.3$ \\
de_la_Vedova Glacier & 56.83 & $-0.15 \pm 0.07$ & $-2.4 \pm 1.1$ \\
Bahia_Broken Glacier & 53.22 & $-0.1 \pm 0.08$ & $-1.8 \pm 1.3$ \\
CDI_150 Glacier & 52.31 & $-0.02 \pm 0.07$ & $-0.3 \pm 1.2$ \\
CDI_456 Glacier & 51.22 & $-0.03 \pm 0.09$ & $-0.5 \pm 1.5$ \\
Darwin Glacier & 45.61 & $-0.18 \pm 0.07$ & $-3.6 \pm 1.3$ \\
Cuevas Glacier & 45.27 & $-0.06 \pm 0.08$ & $-1.2 \pm 1.6$ \\
CDI_455 Glacier & 37.73 & $0.02 \pm 0.08$ & $0.4 \pm 2.0$ \\
Oblicuo Glacier & 29.81 & $0.02 \pm 0.08$ & $0.6 \pm 2.4$ \\
CDI_48 Glacier & 28.58 & $-0.04 \pm 0.05$ & $-1.3 \pm 1.5$ \\
CDI_142 Glacier & 26.79 & $-0.05 \pm 0.07$ & $-1.8 \pm 2.3$ \\
\hline "Northern" side & 1322 & $-3.0 \pm 1.0$ & $-1.9 \pm 0.7$ \\
"Southern" side & 1283 & $-1.3 \pm 0.6$ & $-1.0 \pm 0.4$ \\
Entire CDI & 2605 & $-4.3 \pm 1.3$ & $-1.5 \pm 0.6$ \\
\hline
\end{tabular}

sets at $30 \mathrm{~m}$ resolution. The images are orthorectified to an 13/11/2007 ASTER DEM with Rational Polynomial Coefficients (RPCs). Orthorectifying to a more recent ASTER DEM rather than the SRTM DEM minimizes errors caused by pronounced thinning.

\subsubsection{Advanced Land Observing Satellite (ALOS)}

We use L-band SAR pixel-tracking (e.g., Rignot, 2008; Strozzi et al., 2008; Rignot et al., 2011) from two 46 day, ascending ALOS pairs (28/09/2008-13/11/2008 and 04/01/2011-19/02/2011) to produce ice velocities for several CDI glaciers. The ALOS SAR images have an initial pixel resolution of $3.3 \mathrm{~m}$ (azimuth) by $8.3 \mathrm{~m}$ (range). The offsets have an effective resolution of approximately $150 \mathrm{~m}$ (azimuth) by $200 \mathrm{~m}$ (range), based on the step size of 50 pixels (azimuth) by 25 pixels (range). The Synthetic Aperture RADAR (SAR) images cover a broader area than the optical images and are not limited by cloud cover, providing velocities at many glaciers with no ASTER observations. SAR pixel-tracking also performs well in the snow-covered, high-altitude accumulation zone where optical images lack trackable features. The ALOS pairs fail to capture the high speeds near the fronts of several glaciers due to decorrelation caused by strain and possibly melting.

Raw ALOS SAR data are processed using ROI_PAC and offsets are produced by "ampcor". The results are SNRfiltered and run through the elevation-dependent correction 


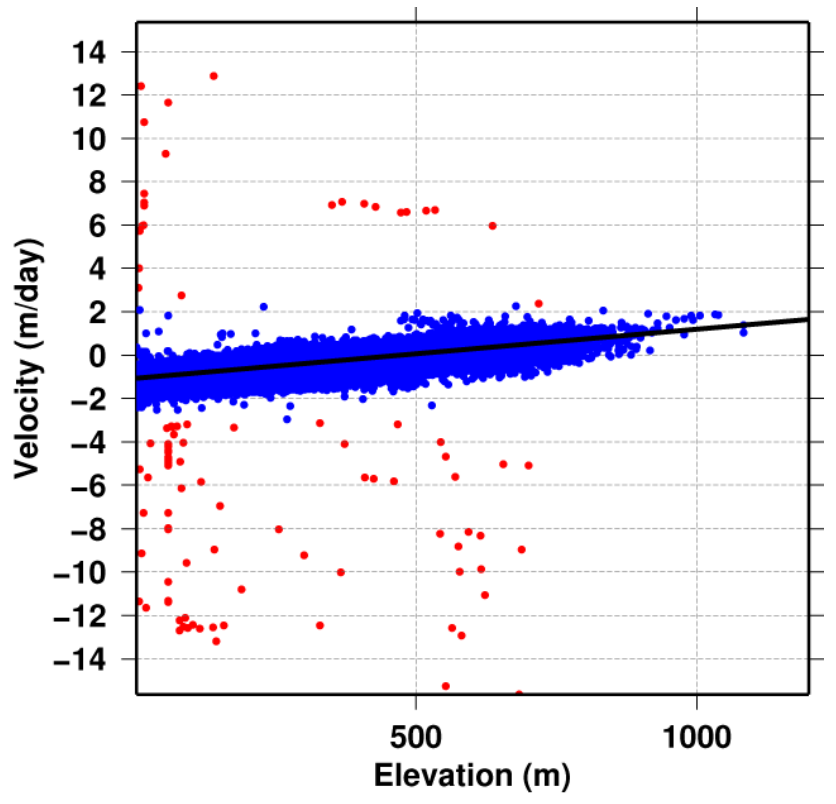

Fig. 5. Scatter plot of E-W "bedrock" velocities for the 07/09/2001 to $25 / 09 / 2001$ ASTER pair. The black line shows the linear trend fitted to the blue points, this is removed from the overall E-W velocity results. Red points are excluded when fitting the trend (they are greater than $\pm \sigma$ from the median value). This cutoff makes a negligible difference in the trend for this pair, but for other pairs it can change the trend significantly (e.g., $>1 \mathrm{~m} \mathrm{day}^{-1}$ per $1000 \mathrm{~m}$ elevation).

routine. ALOS interferometry does not yield velocities due to the relatively large motions, long separation between scenes, and changing surface characteristics.

\subsubsection{Orthorectification errors from thinning}

Pronounced thinning can cause orthorectification errors in optical imagery that do not appear in the off-ice velocities. The longer the timespan between the acquisition date of imagery used to measure offsets and the DEM used to orthorectify the imagery, the greater the error. Our standard processing uses the SRTM DEM, acquired in February 2000, to orthorectify the ASTER L1B images used for pixel-tracking. Examining our $\frac{\mathrm{d} h}{\mathrm{~d} t}$ results (Fig. 1) reveals this to be a potential problem over the three most rapidly thinning glaciers: Marinelli, CDI-08 and Darwin. For Marinelli Glacier we mitigate this effect by orthorectifying QuickBird 2 imagery from 2011 to a 2007 ASTER DEM rather than the SRTM DEM. Furthermore, the difference in incidence angle between the two QuickBird 2 images is less than 0.2 degrees. This means the base/height $(B / H)$ ratio (e.g., Fujisada et al., 2005) is low $(0.003)$ and the pair is insensitive to DEM errors or elevation change between the time of the DEM and the time of image acquisition.

The two ASTER pairs for which we obtain front speeds at Marinelli are from 2001 (07/09/2001-25/09/2001) and 2003
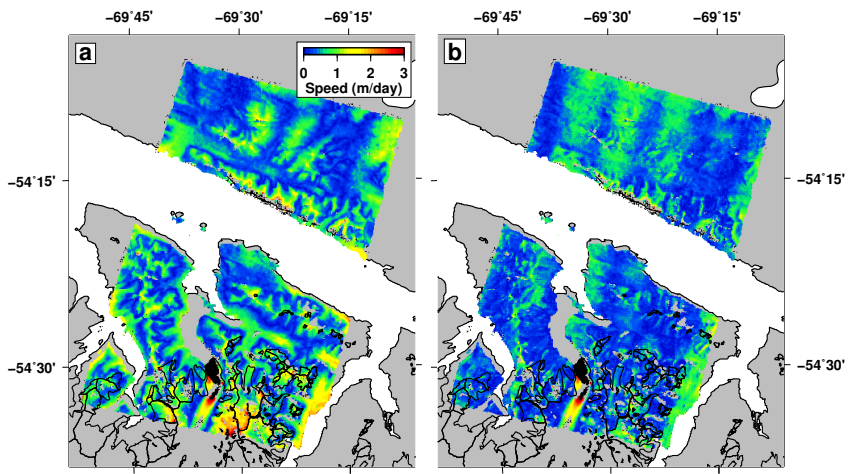

Fig. 6. Effect of elevation-dependent velocity correction for 07/09/2001 to 25/09/2001 ASTER image pair covering Marinelli Glacier. Glacier outlines in black, bedrock in gray (correction is not applied to water pixels). (a) Is a map of speeds with no correction applied, (b) is a map of speeds with correction applied. Correction reduces bedrock motion, the mean and standard deviation for the entire pair drops from $0.6 \pm 0.4 \mathrm{~m} \mathrm{day}^{-1}$ for the uncorrected speeds to $0.4 \pm 0.3 \mathrm{~m} \mathrm{day}^{-1}$ for the corrected speeds.

(06/09/2003-13/09/2003). We co-register the earlier image in each of these pairs to the later image, and orthorectify using the DEM of the later image. Orthorectifying the ASTER imagery to the coincident ASTER DEM minimizes disparity due to DEM errors (with error due to thinning almost entirely removed) and difference in incidence angle between the ASTER images (e.g., Scherler et al., 2008, equation 1).

Front speeds are captured for the Darwin Glacier from a 7 day ASTER image pair in $2001(25 / 09 / 2001$ to 02/10/2001). For this pair we orthorectify to the SRTM DEM as the time between SRTM acquisition and the ASTER pair is fairly short. The direction of the velocity vectors are consistent with glacier flowlines visible in the ASTER imagery providing confidence in the result. Velocities over CDI-08 are from radar pixel-tracking, orthorectification errors are not a concern because radar images are not orthorectified.

\subsubsection{Marinelli Glacier - Flux}

We calculate flux along transects perpendicular to glacier flow (as close as possible to the front) for velocities from $07 / 09 / 2001$ to $25 / 09 / 2001,06 / 09 / 2003$ to $13 / 09 / 2003$ and $30 / 07 / 2011$ to $16 / 08 / 2011$. The height of the glacier is determined from the 25/09/2001 ASTER DEM for the 2001 pair, 13/09/2003 ASTER DEM for the 2003 pair, and the 13/11/2007 ASTER DEM for the 2001 pair (adjusted to 2011 using our $\frac{\mathrm{d} h}{\mathrm{~d} t}$ ). The 25/09/2001 and 13/09/2003 ASTER DEMs do not need to be adjusted because they are coincident with one of the images in the velocity pairs they are being used to orthorectify, and the maximum interval is 18 days (for the 2001 pair). We assume an average glacier depth below water of $150 \mathrm{~m}$ (see Koppes et al., 2009, Fig. 4a and b). Adding this to the height gives an approximate thickness. We multiply the glacier thickness by the perpendicular velocity 
along the transect to calculate flux. Sources of uncertainty that we include in the uncertainty for our flux estimates are the uncertainties on the speed, uncertainty on the depth below water $( \pm 50 \mathrm{~m})$, and uncertainty on the DEMs used to obtain elevations.

\section{Results}

\subsection{Elevation change rates}

Figure 1 provides a map of $\frac{\mathrm{d} h}{\mathrm{~d} t}$ for the CDI. Thinning is concentrated at lower elevations at the front of several tidewater glaciers. Thickening is apparent on the southern side of some of the highest mountains and at the front of the advancing Garibaldi Glacier. We calculate a $\frac{\mathrm{d} V}{\mathrm{~d} t}$ of $-4.2 \pm 1.7 \mathrm{~km}^{3} \mathrm{yr}^{-1}$ for the CDI (extent shown in Fig. 1). This rate equates to an area averaged $\frac{\mathrm{d} h}{\mathrm{~d} t}$ of $-1.6 \pm 0.7 \mathrm{~m} \mathrm{yr}^{-1}$. Our estimate of the sub-aqueous volume loss rate $\left(-0.12 \pm 0.06 \mathrm{~km}^{3} \mathrm{yr}^{-1}\right)$ provides an additional $(\sim 3 \%)$ loss, giving a final $\frac{\mathrm{d} V}{\mathrm{~d} t}$ of $-4.3 \pm 1.7 \mathrm{~km}^{3} \mathrm{yr}^{-1}$, equivalent to a mass loss rate of $-3.9 \pm 1.5 \mathrm{Gt} \mathrm{yr}^{-1}$, assuming surface elevation changes are not due to densification processes and assuming an ice density of $900 \mathrm{~kg} \mathrm{~m}^{3}$. This corresponds to an overall averaged thinning rate of $-1.5 \pm 0.6 \mathrm{~m}$ w.e. $\mathrm{yr}^{-1}$. The ablation zone, which comprises $60 \%$ of the icefield, accounts for $76 \%$ of the mass loss. The ablation zone has an average thinning rate of $-1.8 \pm 0.6 \mathrm{~m}$ w.e. $\mathrm{yr}^{-1}$ (including sub-aqueous mass change), the accumulation zone has an average rate of $-0.9 \pm 0.3 \mathrm{~m}$ w.e. $\mathrm{yr}^{-1}$. Three glaciers (Marinelli Glacier, Darwin Glacier, and CDI-08 Glacier) account for $31 \%$ of the mass loss, but cover only $12 \%$ of the icefield area.

We estimate a thinning rate of $-1.0 \pm 0.4 \mathrm{~m}$ w.e. $\mathrm{yr}^{-1}$ for the southern side, which is lower than the northern side $\left(-1.9 \pm 0.7 \mathrm{mw}\right.$ we. $\left.\mathrm{yr}^{-1}\right)$. The contrast between north and south is most likely due to warming in the north and changing weather patterns that have increased precipitation on the windward side of the mountains and decreased precipitation on the lee side (e.g., Holmlund and Fuenzalida, 1995), and of course the combination of climate with dynamic instability at glaciers such as Marinelli (e.g., Holmlund and Fuenzalida, 1995; Porter and Santana, 2003; Koppes et al., 2009). Table 1 gives the $\frac{\mathrm{d} V}{\mathrm{~d} t}$ for the 16 largest glaciers, with rates for the entire basin, the accumulation zone and the ablation zone.

\subsection{Velocities}

Pixel-tracking provides useful velocities from twenty ASTER image pairs, one QB02 pair and two ALOS pairs with acquisition dates between August 2001 and August 2011 (Fig. 7). ASTER pixel-tracking results are generally better over the northern half of the CDI as there is less cloud cover than to the south (Holmlund and Fuenzalida, 1995; Strelin and Iturraspe, 2007). Composite speed results are

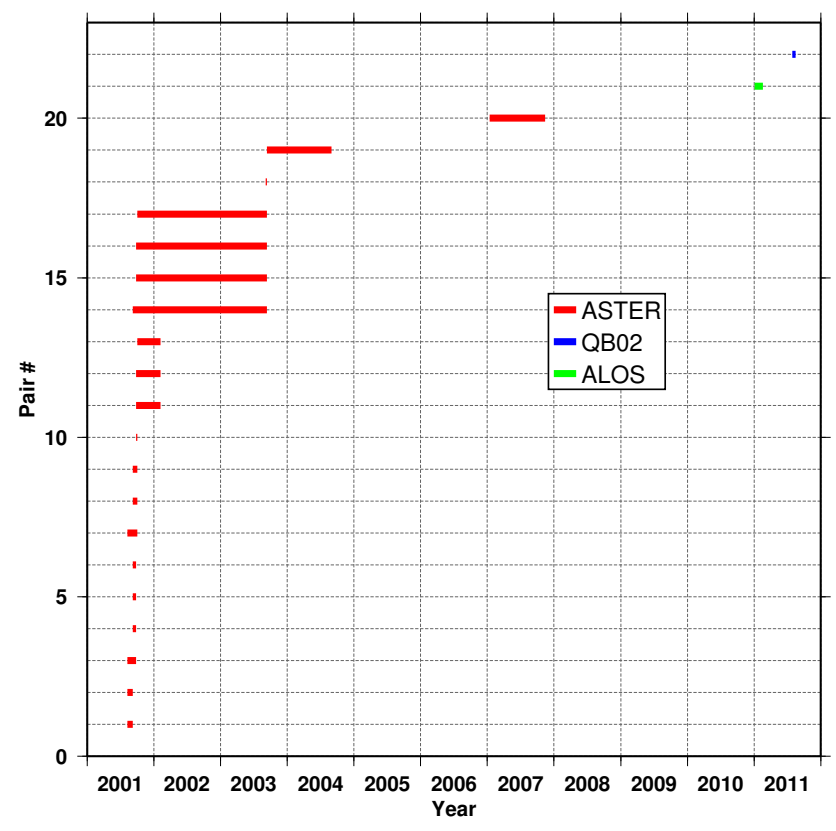

Fig. 7. Date intervals for 22 pairs that produce usable pixel-tracking results. The most recent is a QB02 pair (blue), the next most recent is an ALOS pair (green), and the remainder are ASTER pairs (red).

shown in Fig. 8, velocities for individual pairs over selected glaciers are shown in Fig. 9.

Average front speeds for the tidewater Marinelli Glacier $\left(133 \mathrm{~km}^{2}-\right.$ the largest glacier of the CDI, e.g., Koppes et al., 2009) are obtained between $07 / 09 / 2001$ and 25/09/2001 (18 days) and 06/09/2003-13/09/2003 (7 days) from optical image pairs acquired by ASTER. In order to capture recent rapid motions at the front, we process a 30/07/2011 to $16 / 08 / 2011$ QB02 pair. Figure 10 shows a map of the 2011 velocities from the QB02 pair, along with longitudinal speed profiles for the QB02, 2001 ASTER, 2003 ASTER and 04/01/2011-19/02/2011 ALOS pairs, highlighting the consistently high front speeds from 2001 to 2011. Speeds at the front reach a maximum of $\sim 7.5 \pm 0.2 \mathrm{~m} \mathrm{day}^{-1}$ in 2001, $\sim 9.5 \pm 0.6 \mathrm{~m} \mathrm{day}^{-1}$ in 2003 and $\sim 10 \pm 0.3 \mathrm{~m} \mathrm{day}^{-1}$ in 2011.

Speeds at the front of the tidewater Darwin Glacier $\left(46 \mathrm{~km}^{2}\right)$ reach a maximum average of $9.7 \pm 0.8 \mathrm{~m} \mathrm{day}^{-1}$ for the period $25 / 09 / 2001$ to $02 / 10 / 2001$. No repeat measurements of motion from ASTER pairs are available for the Darwin Glacier. CDI-08 $\left(127 \mathrm{~km}^{2}\right)$, the furthest west and south of the three most rapidly thinning glaciers, reaches speeds of $2.0 \pm 0.5 \mathrm{~m} \mathrm{day}^{-1}$ within $1 \mathrm{~km}$ of its $15 / 01 / 2011$ front (04/01/2011 to 19/02/2011 ALOS pair), unfortunately repeat speeds are not available for this glacier. 


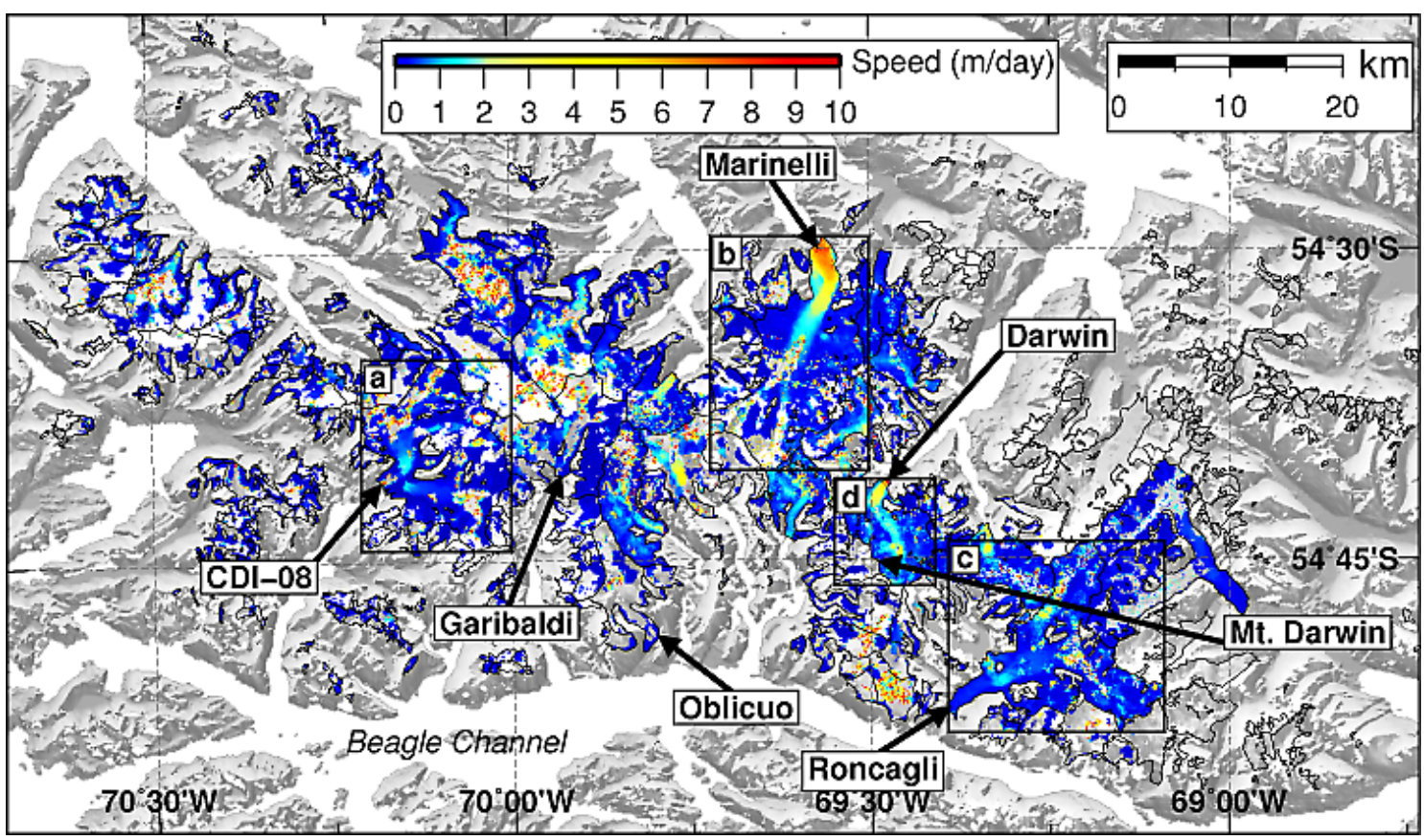

Fig. 8. Composite speed map for the CDI, incorporating ASTER- and ALOS-derived ice velocities.

\section{Discussion}

\subsection{Elevation change rates}

\subsubsection{Individual glaciers}

A longitudinal profile of elevation and thinning rates for Marinelli Glacier (Fig. 11) illustrates both terminus retreat and the dramatic thinning occurring at the glacier. Thinning extends from the terminus to the highest parts of the accumulation zone. The longitudinal profile of the glacier surface remains convex as the glacier thins and retreats (Fig. 11), indicating that basal stresses are relatively high and the front remains grounded (e.g., Koppes et al., 2009) as of 13/11/2007.

The Marinelli Glacier retreated $\sim 4 \mathrm{~km}$ between 2001 and 2011 (measured from ASTER and QB02 imagery), an average rate of retreat of $0.4 \mathrm{~km} \mathrm{yr}^{-1}$. This is lower than the retreat rate of $1 \mathrm{~km} \mathrm{yr}^{-1}$ measured by Koppes et al. (2009) during the late 1990s. Our rate is similar to their average rate of $\sim 0.3 \mathrm{~km} \mathrm{yr}^{-1}$ from 1960 to 2005 . Koppes et al. (2009) infer volume loss rates at Marinelli Glacier from observed retreat rates. A higher retreat rate provides a higher volume loss estimate. They find that the volume change rate dropped from $-0.7 \mathrm{~km}^{3} \mathrm{yr}^{-1}$ in 1997 to $-0.2 \mathrm{~km}^{3} \mathrm{yr}^{-1}$ by 2005 . In contrast, our measurements show that volume loss at Marinelli is sustained at an average rate of $-0.7 \pm 0.2 \mathrm{~km}^{3} \mathrm{yr}^{-1}$ until at least 2007.

The accumulation area ratio (AAR) of Marinelli Glacier is 0.38 at an ELA of $1100 \mathrm{~m}$ (Fig. 12b). Marinelli underwent a significant reduction in AAR as the ELA moved up to its current altitude, likely contributing to the period of neg- ative mass balance in the mid-1990s preceding the current phase of rapid retreat (e.g., Koppes et al., 2009). The AAR has already moved through the part of the hypsometry curve where small changes in elevation lead to large changes in the AAR, an increase of $200 \mathrm{~m}$ from the current ELA of $1100 \mathrm{~m}$ would only reduce the AAR from 0.38 to 0.31 . The negative mass balance operates in conjunction with dynamic instability; now that large changes in the ELA have relatively little affect on the AAR, the continued recession of Marinelli Glacier will likely be even more dependent on the underlying fjord bathymetry.

The tidewater Darwin Glacier has a similar thinning profile to the Marinelli Glacier (Fig. 13), retreating $\sim 2 \mathrm{~km}$ from $22 / 02 / 2000$ to $15 / 01 / 2011$. The $15 / 01 / 2011$ profile is convex for Darwin Glacier, suggesting that the front remains grounded (e.g., Benn and Evans, 1998; Koppes et al., 2009). The retreat and thinning at Darwin Glacier, as for Marinelli Glacier, is characteristic of other fast-moving temperate tidewater glaciers (Koppes et al., 2009). Examples include Jorge Montt, HPS-12 and Upsala glaciers on the SPI (Willis et al., 2012b, see Figs. 1 and 2; Sakakibara et al., 2013). Upsala calves into a lake, but its pattern of thinning and retreat is similar to Jorge Montt and HPS-12.

CDI-08, the third glacier with a strong thinning signal, is on the southern side of the icefield and faces west. This position and aspect favors increased snowfall in the prevailing climate (Holmlund and Fuenzalida, 1995). Given its location and the direction it is facing, CDI-08 is somewhat anomalous in that almost $2 \mathrm{~km}$ of retreat has occurred and the glacier has thinned rapidly between 2001 and 2011. The average 

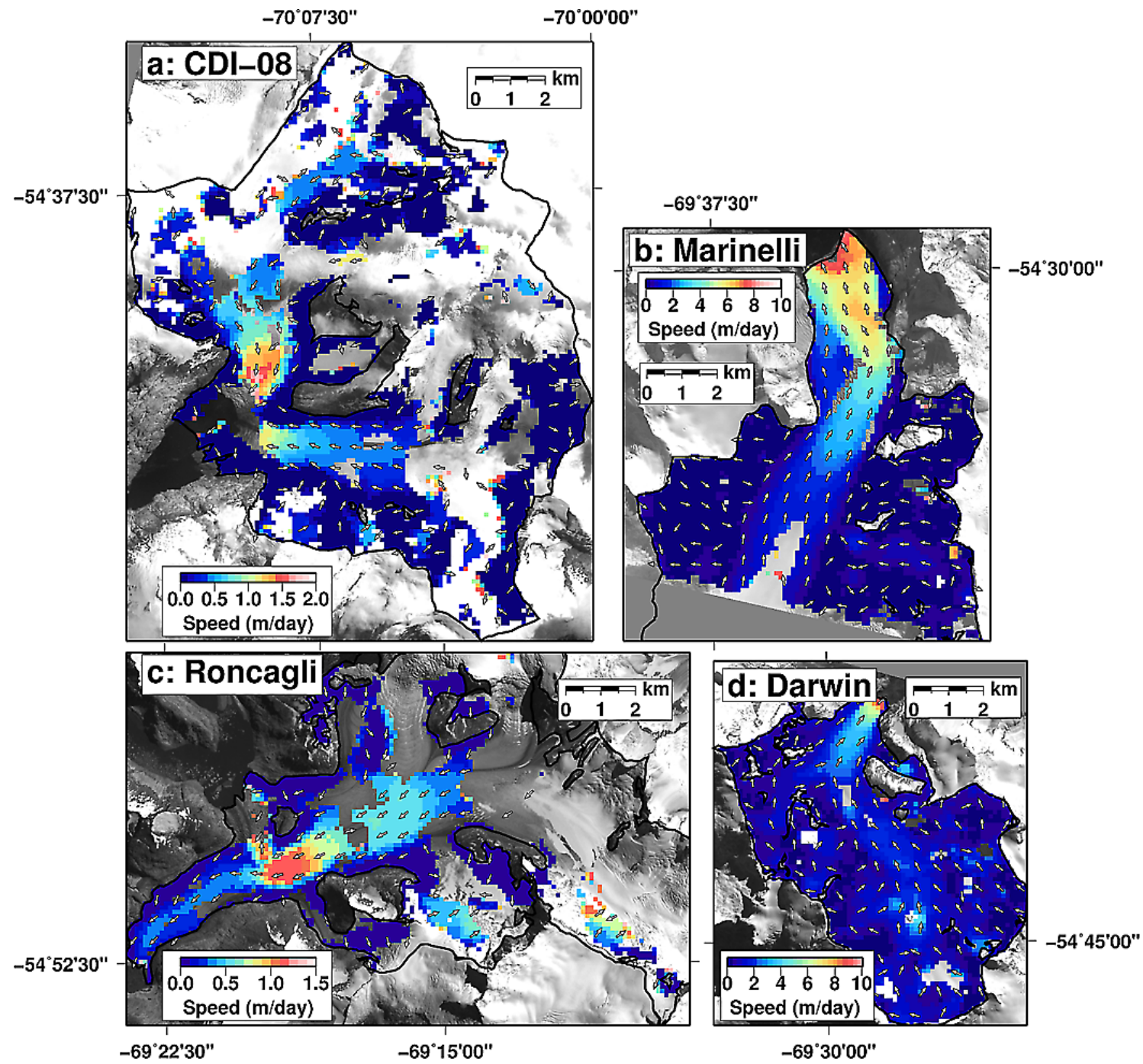

Fig. 9. Velocity maps for individual glaciers (separate color scale for each map), highlighting the quality of the velocity results for individual image pairs. (a) Shows velocities from the 04/01/2011-19/02/2011 ALOS pair for CDI-08 Glacier with an ASTER image from 15/01/2011 in the background. (b) Shows velocities from the 07/09/2001-25/09/2001 ASTER pair for Marinelli Glacier with an ASTER image from 07/09/2001 in the background. (c) Shows velocities from the 04/01/2011-19/02/2011 ALOS pair for Roncagli Glacier with an ASTER image from 02/07/2002 in the background. (d) Shows velocities from the 25/09/2001-02/10/2001 ASTER pair for Darwin Glacier with an ASTER image from 25/09/2001 in the background.

thinning rate for CDI- 08 is $-3.0 \pm 0.9 \mathrm{~m}$ w.e. $\mathrm{yr}^{-1}$, compared to $-1.0 \pm 0.4 \mathrm{~m}$ w.e. $\mathrm{yr}^{-1}$ for the southern part of the CDI.

Garibaldi Glacier, on the southern side of the icefield, with a southern aspect, by contrast, has relatively large areas of positive $\frac{\mathrm{d} h}{\mathrm{~d} t}$ in its ablation zone. Our $\frac{\mathrm{d} h}{\mathrm{~d} t}$ here are based on sparse temporal coverage, and there is only one ASTER image (13/09/2003) that covers the entire front of Garibaldi Glacier. Comparison of a WorldView-1 (optical) image from 09/27/2011 with a 13/09/2003 ASTER image shows that the glacier has advanced by more than $1 \mathrm{~km}$ between 2003 and 2011. Figure 3 shows the frontal variation history of Garibaldi over a $\sim 65 \mathrm{yr}$ period from Landsat TM and aerial imagery, and also shows advance in the past decade. Further confirmation of advance in the past decade comes from field reports in the austral summer of 2007, when the glacier was observed destroying trees and frequently calving (Masiokas et al., 2009). This gives us confidence in the positive $\frac{\mathrm{d} h}{\mathrm{~d} t}$ we observe for Garibaldi Glacier, despite the limited data. The maximum recorded retreat was reached in 2001, followed by advance to the 2011 front that is within $0.5 \mathrm{~km}$ of the 1945 front (the maximum extent Garibaldi during this period), and no more than 2 to $3 \mathrm{~km}$ of retreat/advance in the past $65 \mathrm{yr}$.

The contrast in current behavior between CDI- 08 and Garibaldi may be due partly to the lower ELA of CDI-08 and the higher sensitivity of its AAR to changes in climate compared with Garibaldi (Fig. 12a and c show the AAR versus 

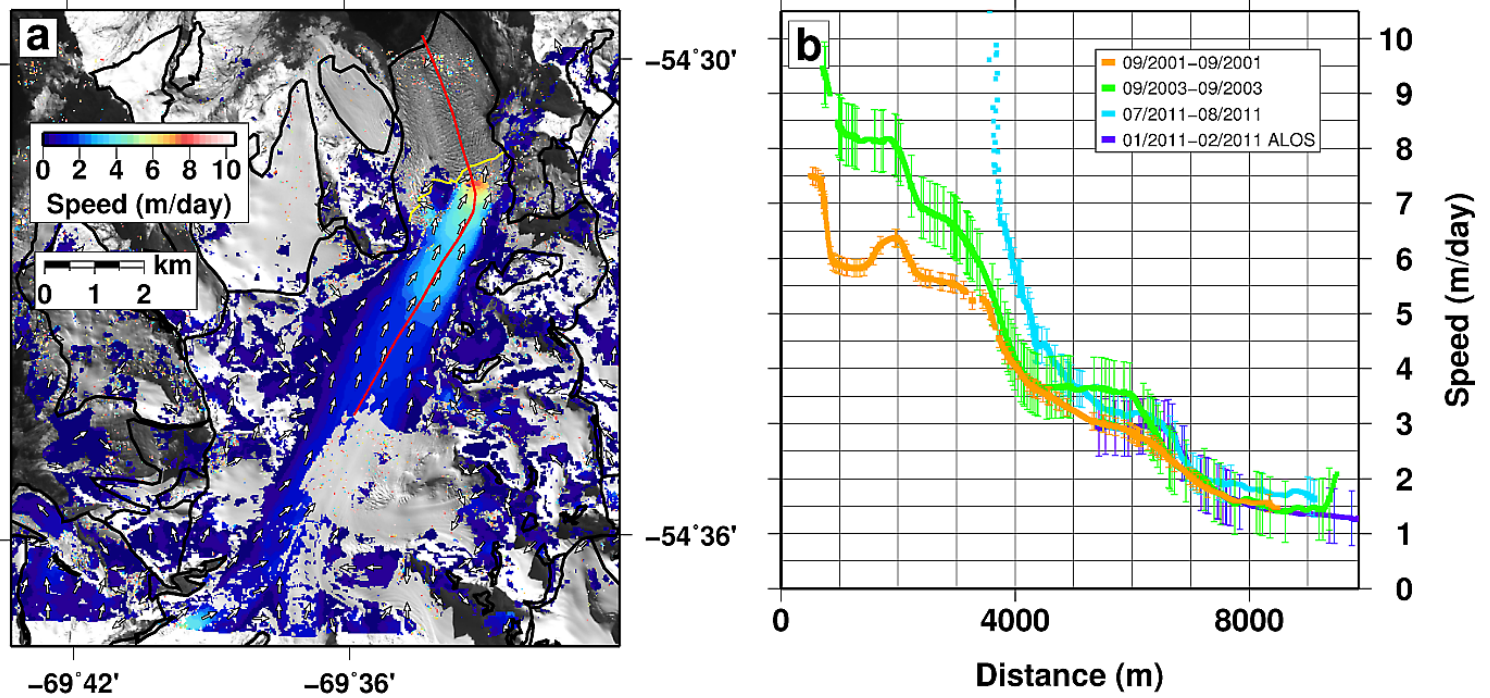

Fig. 10. Speeds for Marinelli Glacier. (a) Is a map of velocities from the QB02 (30/07/2011-16/08/2011) pair (background is the 07/09/2001 ASTER V3N image). (b) Shows profiles (indicated by the red line in a) from two ASTER pairs (07/09/2001-25/09/2001, 06/09/200313/09/2003), the QB02 pair and an ALOS pair (04/01/2011-19/02/2011). The QB02 velocities extend to the 2011 front (shown by the yellow line in a), comparing them with the 2001 ASTER V3N image and the ASTER speed profiles highlights the $\sim 4 \mathrm{~km}$ of front retreat between 2001 and 2011. We measure maximum front speeds at Marinelli Glacier of $7.5 \pm 0.2 \mathrm{~m} \mathrm{day}^{-1}$ in $2001,9.5 \pm 0.6 \mathrm{~m} \mathrm{day}^{-1}$ in 2003 and $\sim 10 \pm 0.3 \mathrm{mday}^{-1}$ in 2011 .
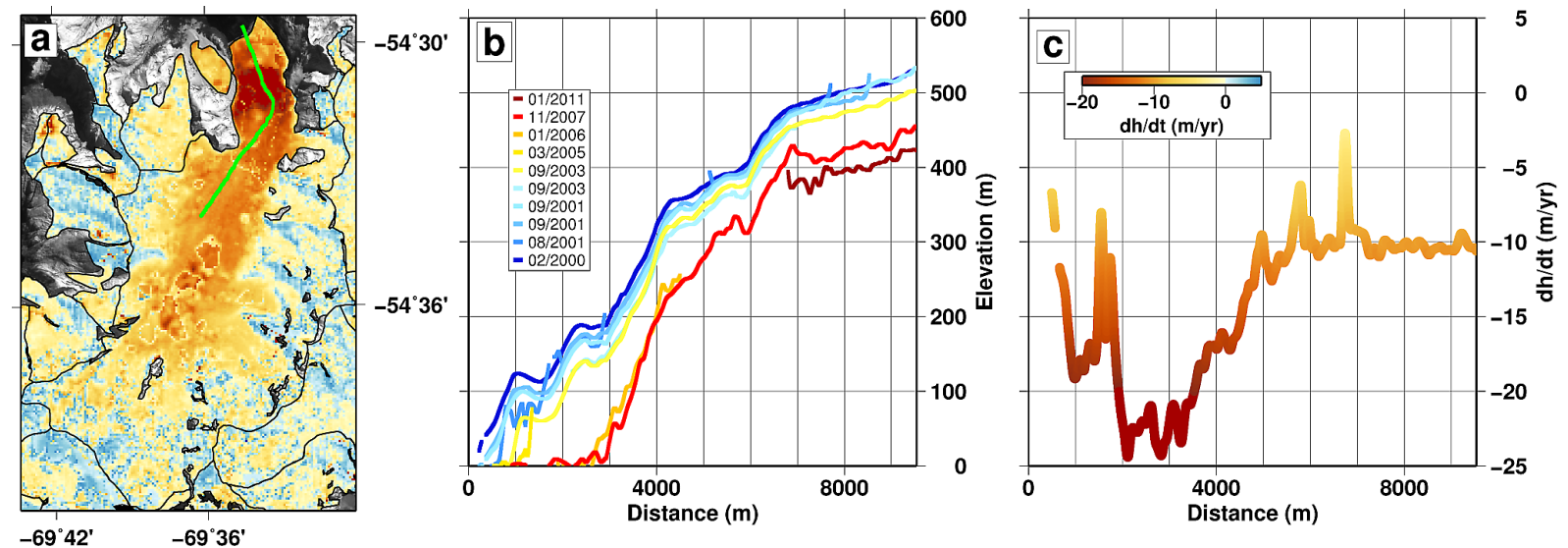

Fig. 11. $\frac{\mathrm{d} h}{\mathrm{~d} t}$ and elevations for a longitudinal profile (starting towards the front) on Marinelli Glacier. A map of $\frac{\mathrm{d} h}{\mathrm{~d} t}$ is shown in (a), the track used in (b) and (c) is plotted in green. (b) Gives elevation profiles for different dates along the green track in (a). The colorscale for the elevation profiles indicates the relative time of acquisition. Dark blue is the SRTM elevation (22/02/2000), the red track extending to the front is an ASTER DEM from 13/11/2007. From the elevation profiles it is clear that the front has retreated between 2-3 km between 2000 and 2007. (c) Shows the $\frac{\mathrm{d} h}{\mathrm{~d} t}$ profile for the green track in (a). The colorscale for (a) is the same as (c).

elevation curves for Garibaldi and CDI-08). At our estimated ELA of $640 \mathrm{~m}$, CDI-08 has an AAR of 0.71; at an ELA of $650 \mathrm{~m}$ Garibaldi has an AAR of 0.89. Shifting the ELA of CDI-08 up to $840 \mathrm{~m}$ reduces the AAR to 0.46 (a reduction of $25 \%$ ), raising the ELA of Garibaldi by more than twice as much to $1090 \mathrm{~m}$ would reduce the AAR to 0.67 (22\%). Post et al. (2011) note that an AAR above 0.8 typically favors an advance in TWG, assuming the ELA of Garibaldi is lower than $900 \mathrm{~m}$, its AAR is greater than 0.8. The behavior of Garibaldi Glacier, with an oscillating, quasi-stable front since at least 1945 is consistent with an AAR that hovers around 0.8 and is relatively insensitive to rising temperatures in the region (e.g., Holmlund and Fuenzalida, 1995; Strelin and Iturraspe, 2007; Lopez et al., 2010).

Our results (positive $\frac{\mathrm{d} h}{\mathrm{~d} t}$ and advance in the ablation zone versus relatively more negative $\frac{\mathrm{d} h}{\mathrm{~d} t}$ in the accumulation zone) indicate the possibility of surge-like behavior (e.g., Rivera et al., 1997). However, a time series of velocities for 
Garibaldi Glacier Hypsometry - AAR vs. Elevation

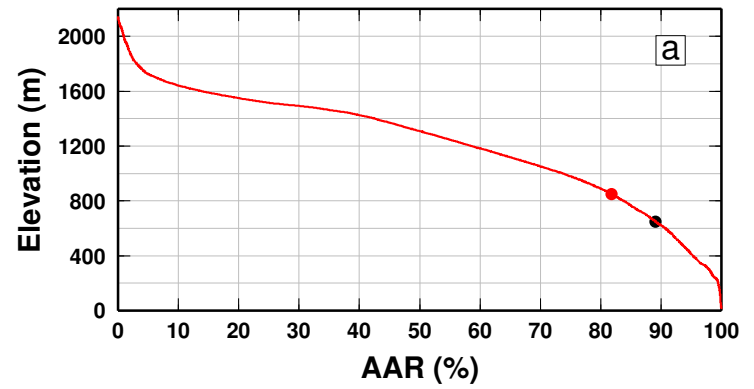

Marinelli Glacier Hypsometry - AAR vs. Elevation
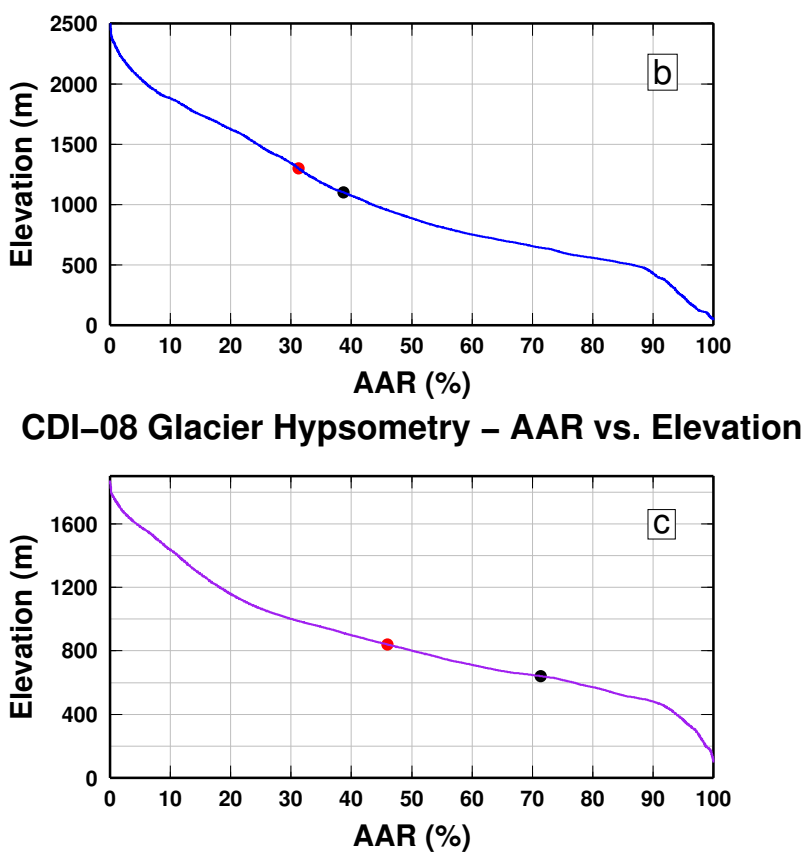

Fig. 12. Hypsometry for Garibaldi (a), Marinelli (b) and CDI-08 (c) glaciers from the SRTM DEM. The curve indicates what the AAR would be for the corresponding elevation. The black dot indicates the current ELA, the red dot indicates a $200 \mathrm{~m}$ upward shft. This would reduce the AAR for Garibaldi Glacier from 0.89 to 0.82 , for Marinelli Glacier form 0.39 to 0.31 , and for CDI-08 Glacier the AAR would drop from 0.71 to 0.46 .

Garibaldi Glacier would be necessary to ascertain whether this is the case. It is important to note that the underlying topography may be playing an important role in regulating Garibaldi's behavior as well, e.g., buoyancy forces at the front may be reduced by a submarine terminal moraine and/or a shallower fjord (e.g., Post et al., 2011).

\subsubsection{Comparison with other southern hemispheric glaciers}

Retreat and thinning is also occurring on other glaciers at similar latitudes in the Southern Hemisphere. Ice masses in the Kerguelen Islands $\left(49^{\circ} \mathrm{S}, 69^{\circ} \mathrm{E}\right)$, for example, ex- perienced accelerating retreat rates and an average $\frac{\mathrm{d} h}{\mathrm{~d} t}$ of -1.4 to $-1.7 \mathrm{~m} \mathrm{yr}^{-1}$ between 1963 and 2000 (Berthier et al., 2009). Glaciers on the subantarctic island of South Georgia $\left(54.5^{\circ} \mathrm{S}, 37^{\circ} \mathrm{W}\right)$ have undergone retreat in response to warming since the 1950s, with recession being particularly pronounced from the 1980s to the mid-2000s (Gordon et al., 2008). Widespread retreat is also observed for the glaciers of Heard Island $\left(53.1^{\circ} \mathrm{S}, 73.5^{\circ} \mathrm{E}\right)$ in the southern Indian Ocean (Thost and Truffer, 2008).

A similar amount of warming has occurred in all these locations, with an increase in average temperature of 0.4 to $1.4^{\circ} \mathrm{C}$ south of $46^{\circ} \mathrm{S}$ in Patagonia since the beginning of the 20th century (Rosenblüth et al., 1995); $1^{\circ} \mathrm{C}$ of warming between 1964 and 1982 for the Kerguelen Islands (e.g., Berthier et al., 2009); approximately $1^{\circ} \mathrm{C}$ of warming from 1950 to mid-1990s on South Georgia (e.g., Gordon et al., 2008); and $0.9^{\circ} \mathrm{C}$ of warming for Heard Island since the mid20th century (e.g., Thost and Truffer, 2008).

At the CDI and SPI, the thinning and rapid retreat of Marinelli and Jorge Montt glaciers from topographic pinning points (Koppes et al., 2009; Rivera et al., 2012) anticipates the predicted response of tidewater glaciers in other regions, such as South Georgia, if warming trends continue (e.g., Gordon et al., 2008, Sect. 5.1).

\subsection{Velocities - Marinelli Glacier}

\subsubsection{Marinelli Glacier - overview}

Below, we estimate flux for Marinelli Glacier using our speeds, then compare our results with Koppes et al. (2009), who estimate the terminus speed and flux of Marinelli from the retreat rate. We find that our results do not agree with Koppes et al. (2009). Whereas they infer a reduction in terminus speed for Marinelli from 2000 to 2005, we find that the front speed in 2003 and 2011 is at least as high as in 2001, and consequently the flux in 2011 is approximately the same as the flux in 2001. We conclude that thinning at Marinelli Glacier is probably dynamic, with bed geometry likely governing velocity and retreat. We then consider Marinelli Glacier as a tidewater-cycle glacier (TWG) in retreat phase (e.g., Meier and Post, 1987; Motyka et al., 2003; Post et al., 2011), and compare it with Jorge Montt Glacier on the SPI.

\subsubsection{Marinelli Glacier - flux}

We estimate a flux of $0.5 \pm 0.2 \mathrm{~km}^{3} \mathrm{yr}^{-1}$ for the 2001 pair, $0.7 \pm 0.2 \mathrm{~km}^{3} \mathrm{yr}^{-1}$ for the 2003 pair and $0.5 \pm 0.2 \mathrm{~km}^{3} \mathrm{yr}^{-1}$ for the 2011 pair. Flux is highest in 2003 (due to higher speeds than 2001 and a larger front than 2011), but the important point is that the 2011 flux has not dropped relative to 2001 due to speeds at the 2011 front that are higher than 2001 and as high as 2003. 


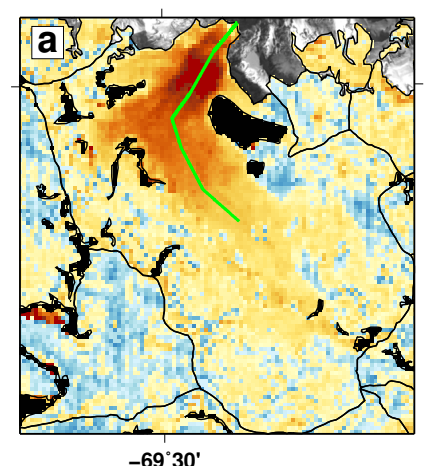

$-69^{\circ} 30^{\prime}$
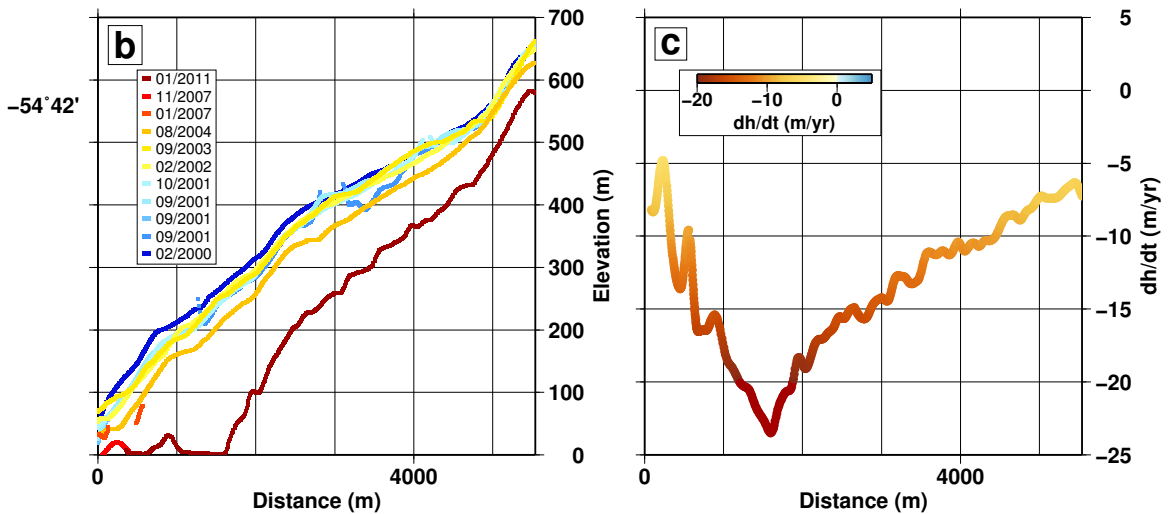

Fig. 13. $\frac{\mathrm{d} h}{\mathrm{~d} t}$ and elevations for a longitudinal profile (starting towards the front) on Darwin Glacier. A map of $\frac{\mathrm{d} h}{\mathrm{~d} t}$ is shown in (a), the track used in (b) and (c) is plotted in green. (b) Gives elevation profiles for different dates along the green track in (a). The colorscale for the elevation profiles indicates the relative time of acquisition. Dark blue is the SRTM elevation (22/02/2000), the red track extending to the front is an ASTER DEM from 15/01/2011. (c) Shows the $\frac{\mathrm{d} h}{\mathrm{~d} t}$ profile for the green track in (a). The colorscale for (a) is the same as (c).

Seasonal changes in conditions at Marinelli Glacier could be influencing our results, we note that the two ASTER pairs from which we obtain front speeds are both from September. However, it is possible that the speeds in September 2001 and 2003 are different due to inter-annual variations in the onset of conditions affecting the glacier speed.

The 2011 QuickBird 2 pair is from 30/07/2011 to $16 / 08 / 2011$. While this is not an entirely different season from the ASTER pairs, it is a month earlier, which is long enough for seasonal variations to possibly play a role in any observed speed differences. We consider it unlikely, however, that a seasonal component of motion is dominant in the $30 \%$ increase in the front speed at Marinelli between September 2001 (7.5 $\left.\mathrm{m} \mathrm{day}^{-1}\right)$ and August $2011\left(10 \mathrm{~m} \mathrm{day}^{-1}\right)$. Unfortunately, we do not have enough repeat measurements to quantify any seasonal effect on speeds, especially given that our ALOS results over Marinelli from the austral summer do not reach the front.

\subsubsection{Marinelli Glacier - comparison with previous results}

Koppes et al. (2009) infer speeds from the retreat rate, with lower retreat rate leading to lower inferred speed. They show Marinelli glacier slowing from a terminus ice speed of $8 \mathrm{~m} \mathrm{day}^{-1}$ in 2001 (similar to our $7.5 \mathrm{~m} \mathrm{day}^{-1} 2001$ speed) to $5.5 \mathrm{~m} \mathrm{day}^{-1}$ in 2003 . Our results, however, are evidence the glacier has not slowed from $2001\left(7.5 \mathrm{~m} \mathrm{day}^{-1}\right)$ to 2003 $\left(9.5 \mathrm{~m} \mathrm{day}^{-1}\right)$. We find that, contrary to the conclusion of Koppes et al. (2009), the front speed and therefore the flux are not decreasing from 2001 to 2003. Furthermore, the front speed in 2011 is higher than 2001, so despite the front being less extensive our estimate of the 2011 flux is as high as for 2001.

\subsubsection{Marinelli Glacier - thinning gradient maintains surface slope at the front}

The maintenance of relatively high speeds at the front of Marinelli Glacier between 2001 and 2011 can be attributed, in part, to the observed gradient in $\frac{\mathrm{d} h}{\mathrm{~d} t}$. There is rapid thinning and retreat at the front, with slower thinning rates upstream. This imbalance maintains surface slope near the glacier front, sustaining the driving stress according to the equation $\sigma=$ $\rho g h \sin (\alpha)$, where $\sigma$ is the driving stress, $\rho$ is the density, $g$ is gravitational acceleration, $h$ is thickness and $\alpha$ is the slope (e.g., Cuffey and Paterson, 2010, p. 295).

\subsubsection{Marinelli Glacier - tidewater cycle}

The rapid retreat noted in this study and covered elsewhere (e.g., Koppes et al., 2009; Warren and Aniya, 1999), coupled with the thinning we observe between 2000 and 2011, suggests that Marinelli Glacier is a tidewater-cycle glacier (TWG) in retreat phase (e.g., Meier and Post, 1987; Motyka et al., 2003; Post et al., 2011). Front recession has opened the fjord at Marinelli. Around 1945 retreat began as the glacier receded into deeper water from the arcuate terminal moraine it had been pinned at, with particularly rapid retreat throughout the 1990s and 2000s (Holmlund and Fuenzalida, 1995; Porter and Santana, 2003; Koppes et al., 2009). Fjord bathymetry (and possibly ocean temperatures) likely governs the ice dynamics and calving rate (e.g., Benn et al., 2007; Koppes et al., 2009; Straneo et al., 2010), which probably control thinning at Marinelli (e.g., Koppes et al., 2009). The velocity results for Marinelli Glacier support this hypothesis. The 2011 speeds at Marinelli, which are higher than 2001 and as high as 2003, suggest that the glacier has not yet retreated to fjord depths shallow enough to slow it down. Along with an estimate of the 2011 flux that is as high as 2001, this leads us to predict that Marinelli Glacier will continue 
to retreat at least until it reaches a new topographic pinning point, which would likely cause the terminus speed to fall and calving rates to drop. There is no evidence of accumulation in the recent history of Marinelli Glacier that would compensate the mass loss due to calving. NCEP-NCAR climate model results show that precipitation has decreased at Marinelli Glacier and temperatures have risen (Koppes et al., 2009).

We do not see similar large thinning signals at adjacent glaciers with similar settings, which is further evidence that dynamic instability, and not melt due to a regional increase in atmospheric temperatures, is the main proximate cause of the current thinning at Marinelli. However, warming and decreased precipitation has likely helped trigger the initial retreat and thinning from the terminal moraine and contributed to the recent history of negative mass balance (Holmlund and Fuenzalida, 1995; Porter and Santana, 2003; Koppes et al., 2009).

Jorge Montt Glacier on the SPI is a somewhat analogous TWG, with a grounded front, thinning occurring at approximately the same rate, and a rapidly receding terminus (Rivera et al., 2012; Willis et al., 2012b). As at Marinelli, terminus retreat opened the fjord at Jorge Montt, with subsequent rapid retreat as the glacier receded into deeper water (Rivera et al., 2012). At Marinelli the retreat is thought to have been initiated by thinning linked to climate changes (e.g., Koppes et al., 2009). Though there is a high degree of variability from glacier to glacier on the Patagonian ice fields (Rivera et al., 2012) the similar behavior of these two glaciers in the same region but on different ice fields suggests that changing climate plays a role in retreat and thinning at Jorge Montt as well, given that the retreat was inferred to have been triggered by warming-induced thinning at the fronts of both glaciers.

\section{Conclusions}

We provide the first icefield-wide thinning rates and glacier velocities for the Cordillera Darwin Icefield. We find thinning at an average rate of $-1.5 \pm 0.6 \mathrm{mw}$.e. $\mathrm{yr}^{-1}$ for the CDI between 2000 and 2011 (equivalent to a mass loss rate of $\left.-3.9 \pm 1.5 \mathrm{Gt} \mathrm{yr}^{-1}\right)$ with less thinning in the south $\left(-1.0 \pm 0.4 \mathrm{~m}\right.$ w.e. $\left.\mathrm{yr}^{-1}\right)$ compared to the northern part of the icefield $\left(-1.9 \pm 0.7 \mathrm{~m}\right.$ w.e. $\left.\mathrm{yr}^{-1}\right)$. This pattern of thinning is consistent with climate records that show a warming trend in this region from the 1940s through the 1990s, leading to higher temperatures along with decreased precipitation on the northern side of the icefield and an increase in precipitation on the southern side (Holmlund and Fuenzalida, 1995; Strelin and Iturraspe, 2007; Koppes et al., 2009).

Operating in conjunction with local glacier geometry, rising temperatures triggered a period of prolonged retreat at Marinelli Glacier (since 1945) (e.g., Holmlund and Fuenzalida, 1995; Porter and Santana, 2003; Koppes et al., 2009). Recently, Marinelli Glacier retreated approximately $4 \mathrm{~km}$ from 2001 to 2011, reflected in our $\frac{\mathrm{d} h}{\mathrm{~d} t}$ by the zone of rapid thinning near its front (approximately $-25 \mathrm{~m} \mathrm{yr}^{-1}$ ). Our repeat velocity measurements support the hypothesis that Marinelli is still in a retreat phase. We predict the retreat of Marinelli Glacier until it reaches a new topographic pinning point. Our $\frac{\mathrm{d} h}{\mathrm{~d} t}$ map shows a similar pattern and degree of thinning at Darwin and CDI-08 glaciers, but we do not have the thickness or repeat speed measurements required to estimate flux and decipher whether thinning at these glaciers is dynamic.

All three Patagonian ice fields are losing mass. The NPI, with an average $\frac{\mathrm{d} h}{\mathrm{~d} t}$ of $-1.0 \pm 0.1 \mathrm{~m}$ w.e. $\mathrm{yr}^{-1}$ (Willis et al., 2012b) is thinning at a slower rate than the CDI $\left(-1.5 \pm 0.6 \mathrm{~m}\right.$ w.e. $\left.\mathrm{yr}^{-1}\right)$, which is thinning at approximately the same rate as the SPI $\left(-1.6 \pm 0.1 \mathrm{mw}\right.$.e. $\left.\mathrm{yr}^{-1}\right)$ (Willis et al., 2012b). Other glaciers at the same latitude (e.g., the Kerguelen Islands, the island of South Georgia, and Heard Island) are thinning and retreating, and have undergone a similar degree of warming to Patagonia (Rosenblüth et al., 1995; Gordon et al., 2008; Thost and Truffer, 2008; Berthier et al., 2009). The CDI contributed $0.01 \pm 0.004 \mathrm{~mm} \mathrm{yr}^{-1}$ to sea level between 2000 and 2011. The combined NPI, SPI and CDI ice fields contributed $0.078 \pm 0.008 \mathrm{~mm} \mathrm{yr}^{-1}$ over the same period. This rate compares well with recent GRACE estimates (Jacob et al., 2012), and could be further refined by including, for example, DEMs generated from stereo highresolution imagery. Accurate basin-by-basin knowledge of accumulation rates would also help refine the cutoffs used to exclude spurious elevations, producing better $\frac{\mathrm{d} h}{\mathrm{~d} t}$.

Acknowledgements. ASTER data was provided by the LPDAAC. We thank the Alaska Satellite Facility (ASF) and the Japan Aerospace Exploration Agency (JAXA) for the ALOS data. Supported by NASA grant NNX08AI87G issued through the Science Mission Directorates Earth Science Division. Andrés Rivera and Francisca Bown acknowledge the GLIMS project for providing free satellite imagery in the full glacier inventory and surface variations coming in a separate book chapter, and the FONDECYT project \# 1080320. QuickBird 2 and WorldView 1 images provided by NGA Commercial Imagery Program. Sasha A. Bernstein was partially supported by the Cornell Rawlings Presidential Research Scholars Program.

Edited by: A. Kääb

\section{References}

Ahn, Y. and Howat, I. M.: Efficient Automated Glacier Surface Velocity Measurement From Repeat Images Using MultiImage/Multichip and Null Exclusion Feature Tracking, IEEE T. Geosci. Remote, 49, 2838-2846, 2011.

Arendt, A. A., Echelmeyer, K. A., Harrison, W. D., Lingle, C. S., and Valentine, V. B.: Rapid wastage of Alaska glaciers and their contribution to rising sea level, Science (New York, NY), 297, 382-386, doi:10.1126/science.1072497, 2002. 
Aster, R. C., Borchers, B., and Thurber, C. H.: Parameter Estimation and Inverse Problems, Elsevier Inc., Burlington, MA, 2005.

Bamber, J. L. and Rivera, A.: A review of remote sensing methods for glacier mass balance determination, Global Planet. Change, 59, 138-148, 2007.

Benn, D. I. and Evans, D. J.: Glaciers \& Glaciology, Oxford University Press Inc., New York, 1998.

Benn, D. I., Hulton, N. R. J., and Mottram, R. H.: "Calving laws", "sliding laws" and the stability of tidewater glaciers, Ann. Glaciol., 46, 123-130, 2007.

Berthier, E., Arnaud, Y., Baratoux, D., Vincent, C., and Rémy, F.: Recent rapid thinning of the "Mer de Glace" glacier derived from satellite optical images, Geophys. Res. Lett., 31, L17401, doi:10.1029/2004GL020706, 2004.

Berthier, E., Le Bris, R., Mabileau, L., Testut, L., and Rémy, F.: Ice wastage on the Kerguelen Islands $\left(49^{\circ} \mathrm{S}, 69^{\circ} \mathrm{E}\right)$ between 1963 and 2006, J. Geophys. Res., 114, F03005, doi:10.1029/2008JF001192, 2009.

Berthier, E., Schiefer, E., Clarke, G. K. C., Menounos, B., and Rémy, F.: Contribution of Alaskan glaciers to sea-level rise derived from satellite imagery, Nat. Geosci., 3, 92-95, doi:10.1038/ngeo737, 2010.

Bown, F., Rivera, A., Zenteno, P., Bravo, C., and Cawkwell, F.: First glacier inventory and recent glacier variations of Isla Grande de Tierra del Fuego and adjacent islands in Southern Chile, in: GLIMS book, in press, 2013.

Cuffey, K. M. and Paterson, W. S. B.: The Physics of Glaciers, Butterworth-Heinemann, fourth Edn., 2010.

Davies, B. and Glasser, N.: Accelerating shrinkage of Patagonian glaciers from the Little Ice Age ( AD 1870) to 2011, J. Glaciol., 58, 1063-1084, doi:10.3189/2012JoG12J026, 2012.

Fernandez, R. A., Anderson, J. B., Wellner, J. S., and Hallet, B.: Timescale dependence of glacial erosion rates: A case study of Marinelli Glacier, Cordillera Darwin, southern Patagonia, J. Geophys. Res., 116, F01020, doi:10.1029/2010JF001685, 2011.

Fujisada, H., Bailey, G., Kelly, G., Hara, S., and Abrams, M.: ASTER DEM performance, IEEE T. Geosci. Remote, 43, 27072714, doi:10.1109/TGRS.2005.847924, 2005.

Gao, F., Masek, J., and Wolfe, R. E.: Automated registration and orthorectification package for Landsat and Landsatlike data processing, J. Appl. Remote Sens., 3, 033515, doi:10.1117/1.3104620, 2009.

Gardelle, J., Berthier, E., and Arnaud, Y.: Impact of resolution and radar penetration on glacier elevation changes computed from DEM differencing, J. Glaciol., 58, 419-422, doi:10.3189/2012JoG11J175, 2012.

Gardner, A. S., Moholdt, G., Arendt, A., and Wouters, B.: Longterm contributions of Baffin and Bylot Island Glaciers to sea level rise: an integrated approach using airborne and satellite laser altimetry, stereoscopic imagery and satellite gravimetry, The Cryosphere Discuss., 6, 1563-1610, doi:10.5194/tcd-61563-2012, 2012.

Glasser, N. F., Harrison, S., Jansson, K. N., Anderson, K., and Cowley, A.: Global sea-level contribution from the Patagonian Icefields since the Little Ice Age maximum, Nat. Geosci., 4, 303307, doi:10.1038/ngeo1122, 2011.

Gordon, J. E., Haynes, V. M., and Hubbard, A.: Recent glacier changes and climate trends on South Georgia, Global Planet. Change, 60, 72-84, doi:10.1016/j.gloplacha.2006.07.037, 2008.
Holmlund, P. and Fuenzalida, H.: Anomalous glacier responses to 20th century climatic changes in Darwin Cordillera, southern Chile, J. Glaciol., 41, 465-473, 1995.

Howat, I. M., Smith, B. E., Joughin, I., and Scambos, T. A.: Rates of southeast Greenland ice volume loss from combined ICESat and ASTER observations, Geophys. Res. Lett., 35, L17505, doi:10.1029/2008GL034496, 2008.

Ivins, E. R., Watkins, M. M., Yuan, D.-N., Dietrich, R., Casassa, G., and Rülke, A.: On-land ice loss and glacial isostatic adjustment at the Drake Passage: 2003-2009, J. Geophys. Res., 116, B02403, doi:10.1029/2010JB007607, 2011.

Jacob, T., Wahr, J., Pfeffer, W. T., and Swenson, S.: Recent contributions of glaciers and ice caps to sea level rise, Nature, 482, 514-518, doi:10.1038/nature10847, 2012.

Kääb, A.: Monitoring high-mountain terrain deformation from repeated air- and spaceborne optical data: examples using digital aerial imagery and ASTER data, ISPRS J. Photogramm., 57, 39 $52,2002$.

Kääb, A., Berthier, E., Nuth, C., Gardelle, J., and Arnaud, Y.: Contrasting patterns of early twenty-first-century glacier mass change in the Himalayas, Nature, 488, 495-498, doi:10.1038/nature11324, 2012.

Koppes, M., Hallet, B., and Anderson, J.: Synchronous acceleration of ice loss and glacial erosion, Glaciar Marinelli, Chilean Tierra del Fuego, J. Glaciol., 55, 207-220, doi:10.3189/002214309788608796, 2009.

Koppes, M., Conway, H., Rasmussen, L. A., and Chernos, M.: Deriving mass balance and calving variations from reanalysis data and sparse observations, Glaciar San Rafael, northern Patagonia, 1950-2005, The Cryosphere, 5, 791-808, doi:10.5194/tc-5-7912011, 2011.

Lopez, P., Chevallier, P., Favier, V., Pouyaud, B., Ordenes, F., and Oerlemans, J.: A regional view of fluctuations in glacier length in southern South America, Global Planet. Change, 71, 85-108, doi:10.1016/j.gloplacha.2009.12.009, 2010.

Masiokas, M. H., Rivera, A., Espizua, L. E., Villalba, R., Delgado, S., and Aravena, J. C.: Glacier fluctuations in extratropical South America during the past 1000 years, Palaeogeogr. Palaeocl., 281, 242-268, doi:10.1016/j.palaeo.2009.08.006, 2009.

Meier, M. F. and Post, A.: Fast tidewater glaciers, J. Geophys. Res., 92, 9051-9058, 1987.

Motyka, R. J., O’Neel, S., Connor, C. L., and Echelmeyer, K. A.: Twentieth century thinning of Mendenhall Glacier, Alaska, and its relationship to climate, lake calving, and glacier runoff, Global Planet. Change, 35, 93-112, doi:10.1016/S09218181(02)00138-8, 2003.

Nuth, C. and Kääb, A.: Co-registration and bias corrections of satellite elevation data sets for quantifying glacier thickness change, The Cryosphere, 5, 271-290, doi:10.5194/tc-5-271-2011, 2011.

Porter, C. and Santana, A.: Rapid 20th century retreat of Ventisquero Marinelli in the Cordillera Darwin Icefield, Anales del Instituto de la Patagonia, 31, 17-26, 2003.

Post, A., O’Neel, S., Motyka, R. J., and Streveler, G.: A Complex Relationship Between Calving Glaciers and Climate, EOS Transactions, American Geophysical Union, 92, 2011.

Pritchard, H. D. and Vaughan, D. G.: Widespread acceleration of tidewater glaciers on the Antarctic Peninsula, J. Geophys. Res., 112, F03S29, doi:10.1029/2006JF000597, 2007. 
Quintana, J.: Estudio de los factores que explican la variabilidad de la precipitación en Chile en escalas de tiempo interdecadal, Msc thesis, Universidad de Chile, 2004.

Rasmussen, L. A., Conway, H., and Raymond, C. F.: Influence of upper air conditions on the Patagonia Icefields, Global Planet. Change, 59, 203-216, doi:10.1016/j.gloplacha.2006.11.025, 2007.

Rignot, E.: Changes in West Antarctic ice stream dynamics observed with ALOS PALSAR data, Geophys. Res. Lett., 35, L12505, doi:10.1029/2008GL033365, 2008.

Rignot, E., Echelmeyer, K., and Krabill, W.: Penetration depth of interferometric synthetic-aperture radar signals in snow and ice, Geophys. Res. Lett., 28, 3501-3504, doi:10.1029/2000GL012484, 2001.

Rignot, E., Rivera, A., and Casassa, G.: Contribution of the Patagonia Icefields of South America to sea level rise, Science (New York, NY), 302, 434-437, doi:10.1126/science.1087393, 2003.

Rignot, E., Mouginot, J., and Scheuchl, B.: Ice Flow of the Antarctic Ice Sheet, Science, 333, 1427-1430, doi:10.1126/science.1208336, 2011.

Rivera, A., Aravena, J., and Casassa, G.: Recent fluctuations of Glaciar Pío XI, Patagonia: discussion of a glacial surge hypothesis, Mt. Res. Dev., 17, 309-322, 1997.

Rivera, A., Benham, T., Casassa, G., Bamber, J., and Dowdeswell, J.: Ice elevation and areal changes of glaciers from the Northern Patagonia Icefield, Chile, Global Planet. Change, 59, 126-137, doi:10.1016/j.gloplacha.2006.11.037, 2007.

Rivera, A., Koppes, M., Bravo, C., and Aravena, J. C.: Little Ice Age advance and retreat of Glaciar Jorge Montt, Chilean Patagonia, Clim. Past, 8, 403-414, doi:10.5194/cp-8-403-2012, 2012.

Rolstad, C., Haug, T., and Denby, B.: Spatially integrated geodetic glacier mass balance and its uncertainty based on geostatistical analysis: application to the western Svartisen ice cap, Norway, J. Glaciol., 55, 666-680, doi:10.3189/002214309789470950, 2009.

Rosen, P. A., Henley, S., Peltzer, G., and Simons, M.: Updated Repeat Orbit Interferometry Package, EOS, Transactions American Geophysical Union, 85, 47, doi:10.1029/2004EO050004, 2004.

Rosenblüth, B., Casassa, G., and Fuenzalida, H.: Recent climatic changes in western Patagonia, Bull. Glaciol. Res., 13, 127-132, 1995.

Sakakibara, D., Sugiyama, S., Sawagaki, T., Marinsek, S., and Skvarca, P.: Rapid retreat, acceleration and thinning of Glaciar Upsala, Southern Patagonia Icefield, initiated in 2008, Ann. Glaciol., 54, 131-138, doi:10.3189/2013AoG63A236, 2013.
San, B. T. and Süzen, M. L.: Digital elevation model (DEM) generation and accuracy assessment from ASTER stereo data, Int. J. Remote Sens., 26, 5013-5027, doi:10.1080/01431160500177620, 2005.

Scambos, T. A., Dutkiewicz, M. J., Wilson, J. C., and Bindschadler, R. A.: Application of Image Cross-Correlation to the Measurement of Glacier Velocity Using Satellite Image Data, Remote Sens. Environ., 42, 177-186, 1992.

Scherler, D., Leprince, S., and Strecker, M.: Glacier-surface velocities in alpine terrain from optical satellite imagery - Accuracy improvement and quality assessment, Remote Sens. Environ., 112, 3806-3819, doi:10.1016/j.rse.2008.05.018, 2008.

Straneo, F., Hamilton, G. S., Sutherland, D. A., Stearns, L. A., Davidson, F., Hammill, M. O., Stenson, G. B., and RosingAsvid, A.: Rapid circulation of warm subtropical waters in a major glacial fjord in East Greenland, Nat. Geosci., 3, 182-186, doi:10.1038/ngeo764, 2010.

Strelin, J. and Iturraspe, R.: Recent evolution and mass balance of Cordón Martial glaciers, Cordillera Fueguina Oriental, Global Planet. Change, 59, 17-26, doi:10.1016/j.gloplacha.2006.11.019, 2007.

Strelin, J., Casassa, G., Rosqvist, G., and Holmlund, P.: Holocene glaciations in the Ema Glacier valley, Monte Sarmiento Massif, Tierra del Fuego, Palaeogeogr. Palaeocl., 260, 299-314, doi:10.1016/j.palaeo.2007.12.002, 2008.

Strozzi, T., Kouraev, A., Wiesmann, A., Wegmüller, U., Sharov, A., and Werner, C.: Estimation of Arctic glacier motion with satellite L-band SAR data, Remote Sens. Environ., 112, 636-645, 2008.

Thost, D. E. and Truffer, M.: Glacier Recession on Heard Island, Southern Indian Ocean, Arct. Antarct. Alp. Res., 40, 199-214, doi:10.1657/1523-0430(06-084)[THOST]2.0.CO;2, 2008.

Tucker, C. J., Grant, D. M., and Dykstra, J. D.: NASA Global Orthorectified Landsat Data Set, Photogramm. Eng. Rem. S., 70, 313-322, 2004.

Warren, C. R. and Aniya, M.: The calving glaciers of southern South America, Global Planet. Change, 22, 59-77, 1999.

Willis, M. J., Melkonian, A. K., Pritchard, M. E., and Ramage, J. M.: Ice Loss Rates at the Northern Patagonian Icefield Derived Using a Decade of Satellite Remote Sensing, Remote Sens. Environ., 117, 184-198, doi:10.1016/j.rse.2011.09.017, 2012a.

Willis, M. J., Melkonian, A. K., Pritchard, M. E., and Rivera, A.: Ice loss from the Southern Patagonian Ice Field, South America, between 2000 and 2012, Geophys. Res. Lett., 39, L17501, doi:10.1029/2012GL053136, 2012b. 